\title{
ELEMENTOS SUBJETIVOS DEL DELITO Y LÍMITES DE LAS COMPLIANCE ANTICORRUPCIÓN: A PROPÓSITO DE LA DIFÍCIL DELIMITACIÓN ENTRE GASTOS DE REPRESENTACIÓN Y PAGOS DE FACILITACIÓN*
}

\author{
Miriam Cugat Mauri**
}

Resumen: Para que una compliance sea eficaz debe prescribir pautas de actuación claras y precisas que se erijan en obstáculo cierto a la actuación delictiva. Frente a ese desiderátum las compliance anticorrupción presentan algunas vías de agua. Por un lado, los contornos de las figuras delictivas de las que pueden responder las personas jurídicas se

Recibido: abril 2018. Aceptado: junio 2018

* Este artículo se enmarca en la línea de investigación sobre "Responsabilidad penal y política de los partidos" (DER2014-52890-R) y debe buena parte de sus reflexiones al diálogo mantenido con los Profesores Luigi Foffani, Luigi Stortoni e Inma Valeije, durante mi estancia en la Universidad de Módena y Reggio Emilia, a lo largo del año 2017.

** Profesora Titular de Derecho Penal. ORCID ID: 0000-0001-8996-5826. 
desdibujan en sus niveles inferiores, en los que no siempre está clara la frontera entre los gastos de representación y los pagos de facilitación. Por otro lado, el componente subjetivo inherente a estos delitos difícilmente puede ser aprehendido por normas de conducta estandarizadas y susceptibles de controles externos. Ante tales obstáculos, este artículo reflexiona acerca de los límites de las compliance en la prevención de la corrupción.

Palabras clave: programas de cumplimiento, corrupción, gastos de representación, pagos de facilitación

SUBJECTIVE ELEMENTS OF THE CRIME AND LIMITS OF THE

COMPLIANCE ANTICORRUPTION: ABOUT THE DIFFICULT

DELIMITATION BETWEEN ENTERTAINMENT EXPENSES AND

\section{FACILITATION PAYMENTS}

Abstract: In order that compliance program to be effective they have to prescribe clear and precise guidelines of action. Opposite to this desideratum the compliance anticorruption presents some waterways. On the one hand, the contours of the criminal figures of which the legal persons may be subject to criminal liability are blurred in their low levels, in which not always the delimitation between the entertainment expenses and the facilitation payments is clear. On the other hand, the subjective component inherent to these crimes cannot be apprehended by policies standardized and capable of external controls. Before such obstacles, this article reflects on the limits of the compliance in the prevention of the corruption.

Keywords: compliance program, corruption, entertainment expenses, facilitation payments

\section{Introducción}

En la vida de cualquier empresa habrá momentos de contacto con la Administración, sea para la obtención de la licencia de actividades, la adjudicación de contratos, concesiones o subvenciones, o a propósito de inspecciones de trabajo o la seguridad social. De modo que, en principio, cualquiera de ellas estará expuesta al riesgo de corrupción que puede presentarse como la vía rápida o fácil de satisfacer los propios intereses. Ahora bien, que puedan cometerse delitos en nombre y provecho de la 
empresa no significa que ésta quede necesariamente expuesta al riesgo de sanciones penales, ni tan siquiera cuando ello responda a un plan de actuación perfectamente diseñado y orquestado.

Como es sabido, el sistema de incriminación especifica o lista cerrada por el que opta nuestro código penal ${ }^{1}$ restringe las posibilidades sancionatorias a un grupo limitado de delitos del que precisamente queda excluida la abrumadora mayoría de los que atentan contra la función pública. Así, el funcionario que otorga la licencia a la empresa que no la merece, omite la inspección preceptiva o abona un sobreprecio arriesga sanciones penales, como también el particular que actuando en nombre de la empresa le haya inducido, presionado o pagado por ello ${ }^{2}$. Sin embargo, puesto que, acertadamente o no, no se ha previsto la responsabilidad penal de las personas jurídicas (en adelante, RPPJ) para la totalidad de delitos contra la Administración pública, la mayoría quedarán fuera del foco de atención prioritaria de las compliance penales ${ }^{3}$. Así sucede llamativamente con los

1 En adelante, emplearé la expresión "la lista" para referirme de modo abreviado a la relación de tipicidades para las que se prevé la RPPJ, que como es sabido no se hallan reunidas en una única disposición del Código penal sino esparcidas a lo largo del mismo.

Sobre modelos alternativos en Derecho comparado, véase el impecable estudio de SALVO, N., Modelos de imputación penal a personas jurídicas: estudio comparado de los sistemas español y chileno, 2015, https://www. tdx.cat/handle/10803/285167.

2 La participación del extraneus en los delitos (especiales) de corrupción está definitivamente asumida. Por todos, QUINTERO OLIVARES, G., Los delitos especiales: y la teoría de la participación en el derecho penal español, CYMIS, 1974. Es más, los Convenios internacionales instan a la misma como medio de lucha integral contra el fenómeno. Así, art. 27 de la Convención de las Naciones Unidas contra la corrupción, de 2004: "Participación y tentativa. 1. Cada Estado Parte adoptará las medidas legislativas y de otra índole que sean necesarias para tipificar como delito, de conformidad con su derecho interno, cualquier forma de participación, ya sea como cómplice, colaborador o instigador, en un delito tipificado con arreglo a la presente Convención."

3 Por motivos de comodidad y economía lingüística, a lo largo del texto utilizaré la expresión "compliance”, que aunque foránea ha adquirido carta de naturaleza en los escritos especializados, para referirme a lo que en el 
delitos de fraude y negociaciones prohibidas normalmente realizados de consuno con las contratistas y extrañamente excluidos de la RPPJ, además de las falsedades documentales instrumentales a la mayoría de los delitos económicos ${ }^{4}$.

Como excepción a la general impunidad de las personas jurídicas por los delitos que afectan a la función pública ${ }^{5}$ descuellan el cohecho, la corrupción transnacional, el tráfico de influencias o incluso la financiación ilícita de los partidos ${ }^{6}$, que pueden ser la vía por la que aquéllos traten de satisfacer sus intereses crematísticos ${ }^{7}$. Por lo tanto, deberán contemplarse

Código aparece bajo las expresiones "modelos de organización y gestión" o "modelos de organización y de prevención" (art. 31 bis CP).

4 Por consiguiente, en lo que a las personas jurídicas se refiere, estas tipicidades no podrán desarrollar una función de recogida como la que han cumplido en otros lugares como, por ejemplo, en la represión penal de la financiación ilícita de partidos hasta su expresa tipificación en el Código por LO 1/2015. Así, por ejemplo, en el "Caso Filesa", comentado en CUGAT MAURI, M.: "La responsabilidad penal de los cargos de los partidos políticos: alternativas típicas y zonas oscuras", en GARCÍA ARÁN y BOTELLA (Dirs.), Responsabilidad jurídica y política de los partidos en España, Tirant lo Blanch, Valencia, 2018, pág. 249.

5 Acerca de los puntos de confluencia entre las diversas figuras delictivas, CUGAT MAURI, M.: "La responsabilidad penal de los cargos de los partidos", cit. Sobre la posible relación entre la financiación de partidos y corrupción, también, FERNÁNDEZ GARCÍA, J.: "Algunas reflexiones sobre la corrupción política", en FABIÁN CAPARRÓS y PÉREZ CEPEDA, Estudios sobre corrupción, Ratio legis, Salamanca, 2010; y OLAIZOLA NOGALES, I, "«Medidas de regeneración democrática». La nueva regulación de la financiación de los partidos políticos en España", http://revista-estudios.revistas.deusto.es/article/view/186/306.

6 No obstante formalmente, la financiación de partidos políticos no se halle en el Título XIX, sus vínculos con el fenómeno de la corrupción están fuera de toda duda, como pone de manifiesto la mención a la misma en el art. 7.3 de la Convención de las Naciones Unidas contra la corrupción y desarrolla la Guía técnica de las Naciones Unidas contra la Corrupción, 2010, artículo 7, II.6, pág. 18.

7 La responsabilidad de las personas jurídicas (no necesariamente en vía penal) por los delitos de cohecho y tráfico de influencias se prevé también en el art. 18 del Convenio Penal sobre la Corrupción del Consejo de Europa, de 27-11999; art. 2 del Convenio de lucha contra la corrupción de agentes públicos extranjeros en las transacciones comerciales internacionales, 1997; o art. 26 Convención de las Naciones Unidas contra la corrupción de 2004. 
en prácticamente cualquier programa de organización y gestión empresarial.

Con todo, que el Código penal limite la lista de delitos por los que pueden responder las personas jurídicas no significa que éstas no puedan extender sus precauciones a otros más, como muestra de su compromiso con la lucha contra la corrupción ${ }^{8}$, y por qué no su simultáneo interés en evitar la responsabilidad civil subsidiaria por los que cometan sus empleados, dependientes, representantes o gestores (art. 120.4 CP). En especial, cuando la frontera entre los delitos por los que puede responder la persona jurídica y los que no es muy delgada, como lo es la fina línea que separa el delito de tráfico de influencias (con RPPJ) de la inducción a la prevaricación ( $\sin \mathrm{RPPJ})^{9}$.

Volviendo a los delitos estrictamente incluidos en la lista, otro de los problemas a los que deberán enfrentarse las compliance anticorrupción yace en la necesaria delimitación entre lo socialmente adecuado y lo penalmente ilícito, que depende de una conjunción de elementos objetivos, subjetivos y valorativos difícilmente traducibles en unas pautas de actuación completamente estandarizables ${ }^{10}$. Este es el motivo por el que las insistentes apelaciones de las guías de buenas prácticas ${ }^{11}$ al compromiso

8 Desde este punto de vista, la empresa podría extender sus precauciones a la prevención de delitos finales como la prevaricación o la malversación cuando para ello no bastaran las medidas frente a los delitos mediales como el cohecho.

9 Ilustrativo de la proximidad entre ambas figuras fue el fallo del caso Juan Guerra (STS 1312/1994, 24-6), en el que se argumentó que ningún óbice existía a la condena de hechos cometidos antes de la introducción del tipo de ejercicio de influencias cuando la misma conducta podía castigarse como inducción a la prevaricación ya antes de la reforma. Sobre el caso y la sentencia, CUGAT MAURI, M., "El tráfico de influencias en cuatro sentencias", Jueces para la democracia, núm. 28, 1997.

10 Como se afirma en EUROPEAN COMMISSION, Quality of Public Administration. A toolbox for Practitioners, 2017: "faced with conflicts of interest, < doing the right thing > is not always instantly obvious".

11 A modo de ejemplo del alto grado de desarrollo al que se ha llegado en la elaboración de pautas anticorrupción, véase OCDE, UNODC, BANCO MUNDIAL, Ética Anticorrupción y Elementos de Cumplimiento Manual para Empresas, 2013. 
de la empresa con la ética, el rol ejemplar que deben desplegar sus líderes o los sistemas de autorizaciones o controles mutuos entre trabajadores, socios comerciales o filiales ${ }^{12}$ no pueden ser garantía absoluta de certeza y eficacia. Si las pautas de actuación no pueden reconocerse nítidamente ex ante por quienes deben aplicarlas o monitorizarlas de poco servirá el refuerzo del liderazgo, la imposición de sistemas de autorización o el requisito de la doble firma o "four eyes" 13 si sus destinatarios están tan desconcertados juntos como por separado. Mientras persistan las dudas acerca de los precisos contornos de la norma penal, éstas se proyectarán sin remisión alguna sobre los igualmente difusos confines de las normas de cumplimiento empresarial $^{14}$.

A mayor abundamiento, el histórico problema de delimitación del contenido del injusto a partir de criterios tan indeterminados ${ }^{15}$ como el de la adecuación social ${ }^{16}$ se complica con la

$12 \mathrm{Al}$ respecto, Guía de buenas prácticas para los controles internos, la deontología y la conformidad, Anexo 2 al Documento sobre el Convenio OCDE, del Ministerio de economía y competitividad, Ministerio de justicia Madrid, 2015.

13 Críticamente acerca del "Four-eyes principle", véase el interesante trabajo empírico de SCHICKORA, T., "Bringing the Four-Eyes-Principle to the Lab", Munich Discussion Paper No. 2011-3, Department of Economics University of Munich Volkswirtschaftliche Fakultät, Ludwig-MaximiliansUniversität München, http://epub.ub.uni-muenchen.de/12160/.

14 Sobre la necesidad de clarificación de la legislación aplicable, Programa anticorrupción de ética y cumplimiento para las empresas. Guía práctica, UNODC, 2013, pág. 27: "Las empresas deben hacer una amplia investigación sobre las distintas leyes y regulaciones de los países en los que operan"; pág. 36. Sobre las políticas para la prevención de riesgos penales en éste área, OCDE, UNODC, BANCO MUNDIAL, Ética Anticorrupción y Elementos de Cumplimiento Manual para Empresas, 2013, pág. 34 ss.

15 Acerca del obstáculo que suponen los conceptos jurídicos indeterminados en el control de los conflictos de interés se alerta,muy especialmente en el Informe elaborado por la Oficina Antifrau de Catalunya sobre La gestió dels conflictes d'interès en el sector públic de Catalunya, Barcelona, 2016, pág. 22.

16 Criterio que se repite en la mayoría de normas administrativas sobre la admisibilidad de obsequios a funcionarios.En la valoración del cohecho, véase, por ejemplo, SAP Madrid 273/2013, 7-6. 
progresiva extensión del objeto de tutela al mercado y función pública extranjera e internacional a la que instan los Conve$\operatorname{nios}^{17}$, que da entrada a un nuevo orden de valores y principios con el que deberán cohabitar las empresas exportadoras o de matriz internacional ${ }^{18}$.

Frente a todas esas ambigüedades y dilemas interpretativos, y con las miras puestas en la necesidad de contar con pautas de actuación claras y precisas que se alcen en obstáculo cierto a la comisión del delito, este artículo reflexiona acerca de la difícil delimitación entre gastos de representación y pagos de facilitación ${ }^{19}$, entre otros supuestos igualmente problemáticos.

\section{Las dádivas y favores como objeto del delito}

Siendo así que los delitos de cohecho, corrupción internacional, tráfico de influencias y financiación ilícita de los partidos integran la reducida lista de aquellos para los que se prevé la RPPJ, ninguna duda cabe acerca de que los agasajos o retribuciones que los funcionarios o personas físicas o jurídicas de

17 Si bien, como subraya RAMOS RUBIO, C.: "Del delito de cohecho: mano «más» dura «todavía» contra la corrupción nacional e internacional, arts. 419, 420, 421, 422, 423, 424, 425, 426, 427, 430, 439 y 445”, en QUINTERO OLIVARES (dir.), La Reforma Penal de 2010: análisis y comentarios, Aranzadi, Cizur Menor, 2010, pág. 338 ss., los compromisos internacionales no lo explican todo.

18 No entro aquí en el análisis material de la correlación de fuerzas que está tras los supuestos consensos internacionales y el especial poder que en ellos tienen determinados países.

19 A modo de ejemplo de los focos de peligro en abstracto, véase la Guía de buenas prácticas para los controles internos, la deontología y la conformidad, Anexo 2 al Documento sobre el Convenio OCDE, del Ministerio de economía y competitividad, Ministerio de justicia Madrid, 2015 , que obliga a poner especial atención sobre una serie de conceptos de los que no cabe saber ex ante la relevancia penal que en un concreto caso pueden adquirir. Así: "regalos, ii. gastos de alojamiento, de ocio y otros, iii. viajes de los clientes, $i v$. contribuciones políticas, $v$. dones a organismos de caridad y patrocinios, vi. pagos de facilitación, e vii. incitación y extorsión". 
su entorno puedan recibir de las empresas estarán en el punto de mira de los programas de cumplimiento normativo.

Así, a la vista de la necesaria atención que las compliance deben dispensar a tales prácticas, y previa advertencia de la relativa disparidad en la definición del objeto de intercambio en las diversas figuras delictivas, a continuación, se hace mención al contenido propio de cada una de ellas al que deberán atender las pautas anticorrupción.

\subsection{La ambigüedad normativa como problema previo e irreductible}

Por lo general pero muy especialmente en materia de corrupción, el primer problema al que deben enfrentarse las compliance radica en la precisa demarcación de los confines de la conducta prohibida, lastrada por criterios valorativos como la adecuación social o subjetivos como el motivo o destino del favor.

Ante ello cuando deben definirse las pautas de actuación nadie sabe muy bien dónde trazar la línea de separación entre el obsequio permitido y el prohibido. En principio parecerían quedar fuera del punto de mira las atenciones de escaso valor que muchos códigos de conducta hoy sitúan sobre los 100-150 Euros; pero ¿cómo tratar los supuestos en que aquello aparentemente nimio se concede con el fin de estrechar lazos personales con el decisor?, ¿basta con el ánimo corruptor? ¿o que el destinatario sea sensible al mismo?, y viceversa, ¿basta la justificación comercial para declararlos atípicos?

Si bien nadie duda acerca de la improcedencia de obsequiar al órgano decisor con determinado porcentaje sobre los beneficios de la obra, a medida que se desciende en el valor del presente o su beneficiario se aleja del círculo de sujetos con relaciones directas y contrastables con el funcionario competente no sólo aumentan los problemas de prueba de la relación causal o final, sino también los relativos a la legitimidad de su sanción penal y la posibilidad de prevenirlos por medio de las compliance. 
El solo hecho de que la legislación administrativa castigue la recepción de prebendas por parte de los funcionarios ${ }^{20}$ permite anticipar una zona de relevancia extrapenal a la que podrían remitirse los supuestos que, siguiendo a VÁZQUEZPORTOMEÑE, deberían quedar fuera del cohecho de facilitación como los presentes ajenos a las competencias propias del cargo $^{21}$; y por debajo de ella aun una zona de irrelevancia jurídi$\mathrm{ca}^{22}$ por adecuación social ${ }^{23}$.

20 Así, según el Real Decreto Legislativo 5/2015, de 30 de octubre, por el que se aprueba el texto refundido de la Ley del Estatuto Básico del Empleado Público, art. 53.7 (principios éticos) del: "7. No aceptarán ningún trato de favor o situación que implique privilegio o ventaja injustificada, por parte de personas fisicas o entidades privadas"; art. 54.6 (principios de conducta) "6. Se rechazará cualquier regalo, favor o servicio en condiciones ventajosas que vaya más allá de los usos habituales, sociales y de cortesía, sin perjuicio de lo establecido en el Código Penal"; art. 95.2,j) (faltas muy graves): "j) La prevalencia de la condición de empleado público para obtener un beneficio indebido para sí o para otro".

21 En el plano internacional, sobre la diferencia entre uno y otro supuesto, éase la Guía legislativa para la aplicación de la Convención de las Naciones Unidas contra la Corrupción, $2^{\mathrm{a}}$. ed., revisada, 2012, pár. 213, nota 25, que subraya el distinto objeto del delito de corrupción internacional en el Convenio contra la corrupción OCU y el más amplio de la OCDE: “a) En la Convención contra la Corrupción se prevé que el soborno de un funcionario público extranjero se cometería "con el fin de que dicho funcionario actúe o se abstenga de actuar en el ejercicio de sus funciones oficiales". El Convenio de la OCDE se refiere a actos u omisiones "en cumplimiento de sus deberes oficiales", queden o no comprendidos "en el ejercicio de las atribuciones conferidas a tal funcionario".

En profundidad, sobre el concepto de "abuso" funcional, por todos, VÁZQUEZ-PORTOMEÑE SEIJAS, F.: Los delitos contra la Administración Pública. Teoría general, INAP, Universidad de Santiago de Compostela, 2003, págs. 141 ss. Propugnando una configuración restrictiva del cohecho de facilitación para que se circunscriba a los funcionarios con competencia para actuar en favor de los intereses del donante, VÁZQUEZPORTOMEÑE SEIJAS, F.: "Política criminal del cohecho impropio: presupuestos para su reforma en el Código penal español", Diario La Ley, $\mathrm{n}^{\circ} 8526,2015,24-4$ en http://diariolaley.laley.es/ .

22 Art. 54.6 RD 5/2015, 30-10: "Se rechazará cualquier regalo, favor o servicio en condiciones ventajosas que vaya blecido en el Código Penal."

23 Sobre la relevancia del criterio en la definición de los límites del ámbito típico y su inevitable indeterminación, GÓMEZ RIVERO, C.: "Derecho 
El problema radica en que la relativa inaprehensibilidad y volubilidad de los criterios que nos sitúan en uno u otro terreno hará difícil decidir cuándo lo que se presenta como un gasto de representación o promoción comercial deba tenerse por prohibido penalmente como pago de facilitación ${ }^{24}$. Ni el

penal y corrupción: acerca de los límites de lo injusto y lo permitido", en Estudios Penales y Criminológicos, Vol. XXXVII, 2017, con cita de los supuestos en los que se ha planteado la aplicabilidad del criterio. Así, niegan la irrelevancia penal de la conducta enjuiciada: el Auto del TSJ de la Comunidad Valenciana de 15 de julio de 2011 ("Caso Camps"), según el que la entrega de trajes no podía considerarse irrelevante penalmente por adecuación social; por el contrario, afirman la irrelevancia penal de la conducta: el Auto del Tribunal Supremo de 19 de septiembre de 2005 respecto de los obsequios navideños de "valores habituales", la SAP de Islas Baleares, de 5 de marzo de 1997, respecto de las propinas otorgadas al encargado del cementerio, la SAP de Santa Cruz de Tenerife de 3 de junio de 2011 respecto de la entrega de unos video juegos al funcionario de la oficina tramitadora del DNI con el que mantenía relación de amistad.

Al respecto también, Guía legislativa para la aplicación de la Convención de las Naciones Unidas contra la Corrupción Segunda edición revisada, 2012: e) En la Convención contra la Corrupción se afirma el principio de que los medios jurídicos de defensa en el caso de los delitos tipificados con arreglo a ella quedan sujetos al derecho interno de los Estados parte (párrafo 9 del artículo 30). En cambio, con arreglo al Convenio de la OCDE solo son permisibles dos medios jurídicos de defensa en el caso del delito de soborno de un funcionario público extranjero: i) en el caso de los "pequeños pagos para 'facilitar' trámites", y ii) en los casos en que "la ventaja se permite o requiere en la ley escrita o reglamentación del país del servidor público extranjero" (Comentarios al Convenio de la OCDE, párrafos 7 y 8).

24 Distinción de la cual no sólo se deducen consecuencias penales sino también fiscales, por cuanto mientras unos son gastos deducibles, los otros, no. Así, según el art. 15 de la Ley del Impuesto de Sociedades: "No tendrán la consideración de gastos fiscalmente deducibles: e) Los donativos y liberalidades. No se entenderán comprendidos en esta letra e) los gastos por atenciones a clientes o proveedores ni los que con arreglo a los usos y costumbres se efectúen con respecto al personal de la empresa ni los realizados para promocionar, directa o indirectamente, la venta de bienes y prestación de servicios, ni los que se hallen correlacionados con los ingresos. No obstante, los gastos por atenciones a clientes o proveedores serán deducibles con el límite del 1 por ciento del importe neto de la cifra de negocios del periodo impositivo."

Sobre la necesidad de terminar con la deducibilidad de las comisiones corruptas, Recomendación del Consejo para reforzar la lucha contra la 
código penal ni la normativa internacional a la luz de la cual se han dictado las últimas reformas ofrecen criterios muy precisos al respecto ${ }^{25}$, lo que se agrava en contextos de "corrupción o

corrupción de funcionarios públicos extranjeros en las transacciones comerciales Internacionales, adoptada por el Consejo el 26 de noviembre de 2009, VIII; Recomendación del Consejo sobre medidas fiscales para reforzar la lucha contra la corrupción de funcionarios públicos extranjeros en las transacciones comerciales internacionales 25 de mayo de 2009; Informe de evaluación sobre España del Segundo ciclo de evaluación del Consejo de Europa (2004) 7F, de 20 de mayo de 2005,1 pár. 67.

25 Valga como ejemplo la Recomendación No. $R$ (2000) 10 sobre códigos de conducta para funcionarios públicos, que aun teniendo por objeto la concreción de los mandatos anticorrupción en pautas de actuación concretas y precisas, no consigue ir más allá de las genéricas admoniciones acerca de la importancia del que el funcionario actúe de modo imparcial y conforme a la ley o evite situaciones de conflicto de intereses o aceptación de regalos que puedan influir en su función, sin especificar objetos o cuantías concretas. $\mathrm{Al}$ respecto, véase, en especial su art. 18 sobre la prohibición de solicitar o aceptar regalos que puedan influir o parecer influir en la imparcialidad en el ejercicio de la función o que puedan ser o parecer ser una recompensa en el ejercicio de sus responsabilidades públicas. Admitiendo la existencia de zonas de incertidumbre acerca del terreno de lo prohibido, la Recomendación insta al funcionario a que acuda al superior jerárquico, lo que no es sino la demostración de la debilidad de los requisitos a los que se condiciona la afirmación de la ilicitud de la dádiva. Ciertamente la Recomendación prescribe concretas conductas al funcionario, como no aceptar la dádiva, devolverla, reportarla, denunciarla, etc., pero para saber qué dádiva debe devolver debe acudir al resbaladizo criterio de la adecuación social al que se condiciona la eficacia del sistema preventivo.

Idéntica indeterminación se aprecia en las directrices que emanan del art. 8.5 de la Convención ONU contra la corrupción, según el que "Cada Estado Parte procurará, cuando proceda y de conformidad con los principios fundamentales de su derecho interno, establecer medidas y sistemas para exigir a los funcionarios públicos que hagan declaraciones a las autoridades competentes en relación, entre otras cosas, con sus actividades externas y con empleos, inversiones, activos y regalos o beneficios importantes que puedan dar lugar a un conflicto de intereses respecto de sus atribuciones como funcionarios públicos. ", y así se recoge en la Guía legislativa para la aplicación de la Convención de las Naciones Unidas contra la Corrupción Segunda edición revisada, 2012, de acuerdo con la cual, cabe exigir de los funcionarios que declaren, entre otros conceptos, acerca de (pár. 96): “e) Regalos o beneficios importantes". 


\section{concusión $^{26}$ ambiental" ${ }^{17}$ en los que los referentes valorativos brillan por su ausencia.}

También la Foreign Corrupt Practices Act americana permite dejar de lado los pagos conforme a la ley local y de representación, si bien sin concretar mucho más su contenido. Al respecto, véase su $\$ 78 d d-1$ [Section 30A of the Securities \& Exchange Act of 1934]. Prohibited foreign trade practices by issuers, ap (c): "Affirmative defenses It shall be an affirmative defense to actions under subsection (a) or (g) of this section that (1) the payment, gift, offer, or promise of anything of value that was made, was lawful under the written laws and regulations of the foreign official's, political party's, party official's, or candidate's country; or (2) the payment, gift, offer, or promise of anything of value that was made, was a reasonable and bona fide expenditure, such as travel and lodging expenses, incurred by or on behalf of a foreign official, party, party official, or candidate and was directly related to (A) the promotion, demonstration, or explanation of products or services; or (B) the execution or performance of a contract with a foreign government or agency thereof." Es decir, se considera causa de defensa penal, además de que la práctica esté autorizada por las leyes locales, que el gasto sea razonable y realizado de buena fe, como gastos de viaje y alojamiento, y estén directamente relacionados con la promoción, demostración o explicación de productos o servicios, o la ejecución o desarrollo de un contrato. El problema es que lo que sean gastos razonables y de buena fe no es evidente, y sin embargo, será el criterio del que penderá la solución acerca de licitud de los pagos y la adecuación de las normas de conducta, que necesariamente adolecerán de idénticos márgenes de indeterminación. Al respecto, véase por ejemplo, la Foreign Corrupt Practices Act Review Procedure Release, No. 81-01 Date: November 25, 1981, sobre gastos de manutención (que se cubren bajo condición de que la comida acompañe a reuniones de empresa de cierta entidad y el gasto sea adecuado a los usos locales), o gastos de transporte y alojamiento (previamente aprobados) o regalos (también bajo aprobación previa, que no excedan de 500 dólares y sean adecuados a los usos locales). Sobre la exclusión de los gastos de alojamiento y viaje que se justifiquen a la luz del desarrollo del objeto social de la empresa como la organización de cursos de formación, visitas guiadas a las instalaciones de la empresa, etc. véase también Review Procedure Releases, No. 83-02 Date: July 26, 1983; idem, No. 83-03 Date: July 26, 1983; ídem. No. 85-01 Date: July 16, 1985; No. 92-01 Date: February 1992; Foreign Corrupt Practices Act Review Opinion Procedure Release No. 96-01 Date: November 25, 1996 Fore; ídem No.: 04-01 Date: January 6, 2004; ídem. No .: 04-03 Date: June 14, 2004; ídem. No.: 04-04 Date: September 3, 2004; ídem. No.: 07-01 Date: July 24, 2007.

26 Sobre esta figura delictiva, por todos, VALEIJE ÁLVAREZ, I.: “Aspectos problemáticos del delito de concusión (diferencias con el cohecho)", 
En esta tesitura, un modo de afrontar la indefinición normativa podría consistir en contraer el contenido de las compliances a un recordatorio de la lista de delitos para los que está prevista la RPPJ con reiteración del compromiso de la empresa con su prevención y represión, y correspondiente advertencia de las consecuencias laborales y penales que su comisión pudiera comportar. No cabe duda alguna acerca de que con ello se acertaría indefectiblemente en el objeto de preocupaciones penales. Sin embargo, se erraría en el método, pues el problema de identificación del ilícito que se ahorrarían los encargados del diseño de las compliance se descargaría sobre sus aplicadores que ni son ni tienen que ser expertos en derecho penal.

Revista general de derecho, 597/1994; VÁZQUEZ-PORTOMEÑE, F.: "Sobre el cohecho por <actos propios del cargo> y sus relaciones con el delito de exacciones ilegales", Cuadernos de política criminal, 116/2015. Sobre la falta de correspondencia entre quién haya tomado la iniciativa y la denominación "cohecho activo", FABIÁN CAPARRÓS, E.: La corrupción de agente público, cit., pág. $90 \mathrm{~s}$.

$\mathrm{Al}$ respecto, véanse también las reflexiones que hace la Guia legislativa para la aplicación de la Convención de las Naciones Unidas contra la Corrupción, Segunda edición revisada, 2012, pág. 43 acerca de la capacidad de las PYME para resistirse a la corrupción.

Desde el punto de vista de la iniciativa, la diferencia estriba en que, mientras que en la concusión solo puede tenerla el funcionario, en el cohecho, cualquiera de las partes, como también en la corrupción internacional activa. Como se advierte en los Comentarios al Convenio de lucha contra la corrupción de funcionarios públicos extranjeros en las transacciones comerciales internacionales, adoptados por la Conferencia Negociadora el 21 de noviembre de 1997, ap. "Generalidades", aunque el Convenio OCDE, trasladado a nuestro art. 286 ter CP, recoja lo que suele denominarse “corrupción activa", no se emplea esta terminología para no inducir a error acerca de quién pueda tomar la iniciativa, que no se limita al particular.

27 Al respecto, PADOVANI, T.: "Il problema «Tangentopoli» tra normalità dell'emergenza ed emergenza della normalità", Rivista italiana di diritto $e$ procedura penale, núm. 2-3, 1996; FORTI, G.: "L'insostenibile pesantezza della "tangente ambientale": Inattualità di disciplina e disagi applicativi nel rapporto Corruzione-concussione", en Riv. it. dir. e proc. pen., fasc.2, 1996. Sobre su recepción en los documentos europeos, Programa de acción contra la corrupción GMC (96) 95 adoptado por el Comité de Ministros del Consejo de Europa, pág. 29. 
Por ello, aunque algunas voces se han preguntado casi retóricamente si en el fondo una compliance podría reducirse a un mero recordatorio y admonición de los riesgos penales a los que en abstracto puede enfrentarse la empresa, no parece que esa sea la posición del legislador cuando para la exención de pena exige que se hayan "adoptado y ejecutado con eficacia... modelos de organización y gestión" que incluyan "medidas de vigilancia y control idóneas para prevenir delitos" (art. 31 bis. $2,1^{\circ} \mathrm{CP}$ ). Es decir, algo más que la desnuda remisión a las normas penales a las que se confía la función de prevención del delito por medio de la amenaza sancionatoria.

De ahí deriva la necesidad de prescribir o prohibir concretas pautas de actuación no obstante las dudas interpretativas que puedan suscitar las disposiciones legales, y por lo tanto a riesgo de excesos u olvidos. La oscuridad o vaguedad legislativa no es nada nuevo. De modo que las personas jurídicas deberán convivir con la misma zona de incertidumbre penal con la que las personas físicas están acostumbradas a lidiar, con una ventaja quizás respecto de éstas en la medida en que por la vía de las compliance pueden esgrimir su compromiso con el derecho más allá de la evidencia del delito cometido en su seno a modo de protección frente al riesgo del dolus in re ipsa ${ }^{28}$.

Lo que no parece exigible es que, ante la ausencia de certezas absolutas, la empresa deba inclinarse por programas de cumplimiento normativo de carácter maximalista en los que las dudas se resuelvan automáticamente en contra de la libertad de actuación empresarial, cuando ni tan siquiera así podría erradicarse por completo el riesgo de comisión de delitos ${ }^{29}$. Piénsese

28 Llaman la atención al respecto las previsiones del art. 28 de la Convención de las Naciones Unidas contra la corrupción, sobre el Conocimiento, intención y propósito como elementos de un delito, según el que: "El conocimiento, la intención o el propósito que se requieren como elemento de un delito tipificado con arreglo a la presente Convención podrán inferirse de circunstancias fácticas objetivas."

29 En este sentido se pronuncia la OFICINA ANTIFRAU DE CATALUNYA, La gestió dels conflictes d'interès en el sector pública de Catalunya, 
por ejemplo en la hipótesis del funcionario que solicita a la contratista un empleo para un conocido de la familia. Aunque no existe duda alguna acerca de la posibilidad de apreciar el cohecho, en especial si el sueldo no guarda relación con su formación y capacidades, frente a prácticas de esta índole no hay medidas preventivas inquebrantables que valgan, pues si bien puede prohibirse la contratación del propio funcionario o familiares, no puede impedirse de modo absoluto el empleo de cualquiera que alguna vez haya tenido contacto con el funcionario competente o su círculo de amigos y familiares. Ello no obsta la sanción de la conducta por la vía del cohecho. Ahora bien, más difícil es poder prevenirlo a través de un sistema de incompatibilidades y prohibiciones que por su exhaustividad sea insoportable para la empresa.

Así las cosas, admitida la posibilidad de que surjan delitos en las empresas mejor organizadas, éstas deberán asumir su ineludible exposición al proceso penal. Ni la más prudente o temorosa compliance podría ofrecer un escudo inexpugnable ante el riesgo de ser sometida al proceso penal ${ }^{30}$, sin perjuicio de que, en caso de no probarse infracción de regla de conducta alguna ${ }^{31}$ la empresa finalmente quede libre de responsabilidades penales. Reflexión que nos lleva a desechar la necesaria autoimposición de programas preventivos maximalistas y eventualmente suicidas desde el punto de vista empresarial para optar por otros que, sin renunciar a la eficacia, sean más realistas.

Barcelona, 2016, que considera inviable la completa eliminación de riesgos de conflictos de interés y consiguiente corrupción.

30 Otro problema es el de la relativa ineficacia que debe esperarse de cualquier compliance que pretenda lidiar con delitos dolosos, como son la práctica totalidad de los incluidos en la "lista", de los que sólo quedan excluidas algunas modalidades de quiebra, blanqueo, delito medioambiental y financiación del terrorismo. Así, QUINTERO OLIVARES. G.: "Los programas de cumplimiento normativo y el Derecho penal", en DEMETRIO CRESPO (coord.) Derecho penal económico y derechos humanos, UCLM, Tirant lo Blanch, 2018, págs. 111 ss.

31 No entro aquí en el problema procesal de la carga de la prueba, sobre el que, en nuestro país, ya se ha pronunciado la STS 154/2016, 29-2 v. Circular FGE 1/2016. 


\subsection{El contenido de la contraprestación típica en los diversos delitos}

Sin olvidar las dificultades acabadas de mencionar, a continuación, se traen a colación los criterios que sirven para la definición de los favores y dádivas que están en el punto de mira de los delitos de cohecho, corrupción internacional, tráfico de influencias y financiación de los partidos. Sin tales aclaraciones previas, una compliance que obligara a la doble firma, la contabilización del gasto o la comunicación de eventuales irregularidades andaría a tientas acerca de los hechos que debieran estar en su punto de mira y que eventualmente pudieran hacer saltar las alarmas penales.

\subsubsection{Las retribuciones de carácter económico}

a) La retribución económica típica del cohecho, con especial mención a las "revolving doors", "contribuciones filantrópicas" y "patrocinios"

El delito mediante el que históricamente se ha castigado la venalidad del funcionario ha sido el cohecho, en el que el medio de pago ha consistido en una contraprestación material antes formulada como "dádiva", "presente" o "regalo" y, desde la reforma de 2010 como "dádivas", "favores", "regalos" o "retribuciones" (arts. 419 ss CP).

Ninguna duda hay acerca de que tales contraprestaciones pueden consistir en pagos en metálico o en especie que pueden incluir abonos de viajes, obras domésticas o la satisfacción de deudas. De modo que aquí sólo me detendré en algunos supuestos dudosos o problemáticos.

i) Las revolving doors

En ocasiones, el modo de influir sobre la voluntad del funcionario será su promoción laboral en el sector privado, lo que además de poner en peligro el recto ejercicio de su función puede repercutir sobre las reglas del mercado cuando la fluctuación de cargos entre el sector público y el privado (revolving 
doors) abre la puerta al traslado de información, poder e influencias de un lado a otro.

Frente a tales peligros el Derecho administrativo prevé unos "periodos de enfriamiento" 32 . Para los supuestos en que además la oferta laboral está destinada a influir sobre la voluntad del funcionario, cabe la posibilidad de apreciar el delito de cohecho, pero para ello será preciso afirmar la condición de funcionario al tiempo de pacto corrupto. Es decir, sólo cuando constante el cargo se ofrezca la simultánea o posterior contratación en el sector privado [a)], pero no así si el pacto tiene lugar tras el abandono de la función pública [b)] o antes de su toma de posesión [c)].

Sólo en el primer caso [a)] la oferta laboral constante el cargo podría afectar al correcto ejercicio de la función pública del agraciado y permitir apreciar el delito que, siendo de emprendimiento, se consuma con independencia del momento en el que se perciba la dádiva o prebenda cuando así acaece. En el segundo caso [b)], la oferta póstuma no podría llegar a afectar a la función ya terminada e impediría apreciar el delito por mucho que trajera causa de la actuación constante el cargo. Por fin, en el último de los supuestos [c)], no obstante la función pública quedara absolutamente comprometida, no podría apreciarse el tipo penal por impedirlo el principio de legalidad que exige que el beneficiario tenga la condición de funcionario al tiempo de los hechos. Vayamos por partes.

Si la oferta se formulara tras el abandono del cargo [b)] quedaría descartado el cohecho activo antecedente (art. 424 en relación con los arts. 419 y $420 \mathrm{CP}$ ) que exige su proyección sobre un acto futuro que ya no podría realizarse. Similares obstáculos afectan también al cohecho activo subsiguiente descrito en el art. $421 \mathrm{CP}$, por cuanto aun en el controvertido supuesto de

32 Así, art. 15 de la Ley 3/2015, de 30 de marzo, reguladora del ejercicio del alto cargo de la Administración General del Estado o art. 7 de la Ley $13 / 2005$. 
que estuviera abarcado por el art. $424 \mathrm{CP}$, no puede acoger cualquier beneficio que obtenga el funcionario por su actuación antecedente sino solo el que reciba constante el cargo que lo sitúa en posición de lesionar la función. En su caso, el eventual vacío de punibilidad tampoco podría aquí suplirse por la vía del cohecho de facilitación descrito en el art. 422 y al que sí se remite el art. 424 , por cuanto también impone que el beneficiario del favor tenga la cualidad de funcionario al tiempo del ofrecimiento o entrega. A lo sumo, en estos casos podrían infringirse recomendaciones o normas administrativas aplicables durante el llamado "periodo de enfriamiento" 33 , o acudirse al delito de tráfico de influencias si de este modo se pretendiera comprar la influencia que el funcionario conservara sobre su antiguo equipo o entorno.

A idéntica conclusión de atipicidad se llegaría en el segundo de los supuestos excluidos [c], consistente en proponer a un particular para un cargo público a cambio de que, una vez llegado a él, devuelva el favor. Aunque el recto ejercicio de la función pública pueda quedar tan o más condicionado aquí que en los supuestos en que el destinatario de la promoción laboral es ya funcionario y no debe el cargo a nadie, la ausencia de esa cualidad subjetiva al tiempo de la oferta sería un obstáculo legal insuperable. Por este motivo, en los ordenamientos en los que se ha querido castigar esta clase de conductas se han previsto expresamente a través de una figura autónoma ${ }^{34}$.

33 Al respecto, véase el art. 26 de la Recomendación No. $R$ (2000) 10 sobre las condiciones para un abandono del puesto público que no afecte la necesaria imparcialidad en el ejercicio del cargo; asimismo, art. 7 de la Llei 13/2005, de 27 de desembre, del règim d'incompatibilitats dels alts càrrecs al servei de la Generalitat que establece un "periodo de enfriamiento" de dos años, o el art. 15 de la Ley 3/2015, 30-3.

34 Comentarios al Convenio OCDE de lucha contra la corrupción de funcionarios públicos extranjeros en las transacciones comerciales internacionales, adoptados por la Conferencia Negociadora el 21 de noviembre de 1997, núm. 10. 


\section{ii) Las contribuciones a entidades sin ánimo de lucro.}

Continuando con las diversas manifestaciones de las retribuciones en especie, también merecen especial atención las contribuciones a entidades sin ánimo de lucro a las que puede estar vinculado el funcionario ${ }^{35}$, por cuanto podrían dar cobijo al delito de cohecho si su entrega fuera el precio que se paga por la actuación del funcionario ${ }^{36}$.

Dejando para más adelante la cuestión relativa a la problemática prueba del motivo o fin de tales aportaciones, es preciso hacer mención previa al contenido material que pueden revestir a fin de valorar si satisfacen las exigencias del tipo legal.

En la práctica, no todas las aportaciones serán en metálico. En algunos casos, pueden consistir en la puesta a disposición de bienes o servicios. Así, por ejemplo, cuando la empresa que comercializa su producto a través de internet contribuye a campañas de crowfunding o teaming ${ }^{37}$ impulsadas por entidades sin ánimo de lucro, mediante la inclusión de anuncios o canalización de pagos a través de su portal de ventas. En estos casos, podríamos hallarnos ante prestaciones en especie evaluables económicamente que reunirían las cualidades precisas para ser objeto del cohecho. El único óbice a la apreciación del delito procede de las posiciones doctrinales que entienden que es preciso que con ello se favorezca de algún modo al funcionario aun

35 Así se prevé en el art. 8.1, e) de la Llei 13/2005, 27-12, si bien se echa de menos la constancia registral de las concretas entidades sin ánimo de lucro a las que se vinculan los altos cargos, sin lo cual no puede desplegar la esperada función de alerta de riesgos: http://governacio.gencat.cat/ca/ pgov_ambits_d_actuacio/pgov_funcio_publica/alts-carrecs-i-directius/ pgov_registre_alts_carrecs/

En el mismo sentido, art. 13.2, c) de la Ley 3/2015, 30-3.

36 De hecho, la Guía práctica, 2013, pág. 49: “aconseja a las empresas que consideren las contribuciones filantrópicas y los patrocinios como un tipo de gasto especial en su programa anticorrupción”.

37 https://www.teaming.net/ 
cuando la dádiva la reciba un tercero ${ }^{38}$, lo que podría fallar en casos de contribuciones esencialmente filantrópicas.

\section{iii) Los patrocinios}

En cuanto a los patrocinios, especial consideración merece la cuestión relativa a si cabe hablar de donación cuando la empresa patrocinadora obtiene un retorno comercial por su inversión" ${ }^{39}$. Así, por ejemplo, el derecho a "usar el nombre de la organización patrocinada y tener créditos publicitarios en medios, actos y publicaciones" o los derechos derivados de la condición de miembro de la asociación en cuestión ${ }^{40}$. De existir tal intercambio comercial, el gasto podría tener un sentido empresarial que disipara la calificación de corrupción; si bien, en contra, podría argüirse la posible doble dimensión de la contribución, como coste de empresa por un lado ${ }^{41}$ y soborno al funcionario por otro. Sin embargo, aun en el remoto caso de admitir la posibilidad de considerar corrupto el pago que en sí mismo beneficia a la empresa tropezaríamos con seguros problemas de prueba del componente subjetivo sobre el que pivotaría el contenido del injusto.

En suma, si bien los gastos de esponsorización o patrocinio no pueden prohibirse radicalmente por los programas de cumplimiento tampoco pueden dejarse de lado, pues podrían adquirir relevancia penal a partir de la presencia de una motivación ilícita

38 Así, MORALES PRATS, F Y RODRÍGUEZ PUERTA, MJ.: "Comentario al art. 419", en QUINTERO OLIVARES (dir.), Comentarios al Código penal español, Aranzadi, 7. Ed., 2016, pág. 1365.

39 Este es el mismo problema que puede plantearse en el resto de supuestos en que el funcionario está legitimado para percibir cobros del sector privado que puede encargarle conferencias o retribuirlo por sus funciones docentes. Al respecto, véanse las excepciones previstas en los arts. 8 y 11 de la Llei 13/2005, 27-12 o el art. 13 de la Ley 3/2015, 30-3.

40 Supuestos a los que se refiere el Programa anticorrupción de ética y cumplimiento para las empresas. Guía práctica, UNODC, 2013, pág. 49.

41 Distinto es cuando el precio no guarda proporción con el valor de mercado. Respecto de este elemento, véase el "Caso Minutas en el Ayuntamiento de Marbella" (STS 841/2013, 18-11). 
que los llevara al terreno de la corrupción. Ahora bien, ello será difícil cuando el patrocinio reporte un beneficio directo para la empresa, en términos por ejemplo de publicidad, pues no puede elevarse a delito por el solo hecho de complacer al funcionario. Otra cosa es que, dado que los motivos e intenciones quedan fuera del alcance de las pautas de actuación controlables por la empresa, las vías de prevención del delito ${ }^{42}$ serán siempre limitadas.

b) El papel del derecho extranjero en la definición de la licitud del pago en el cohecho transnacional.

Tampoco aquí queda duda alguna acerca de que el art. 286 ter CP incluye pagos en metálico o en especie, a pesar del empleo de distinta terminología respecto del anterior, que aquí alude al "beneficio o ventaja indebido, pecuniario o de otra clase".

La diferencia más notable deriva de la adjetivación de los pagos como "indebidos", que tanto podría entenderse como una redundante llamada de atención a la consustancial injusticia de los que se destinan a condicionar la actuación del funcionario como un modo de restricción del ámbito típico, que es como creo que debe interpretarse a la luz de los instrumentos internacionales. Como se señala en los Comentarios al Convenio OCDE $1997^{43}$, el adjetivo "indebido" cumple la función de dar salida a los posibles conflictos entre ordenamientos, en favor de la atipicidad de los pagos cuando así se reputen en el ordenamiento extranjero. Ello sin perjuicio, por supuesto, de ulteriores vías de restricción de la relevancia penal de los pagos a la luz de los principios de ultima ratio y adecuación social, sobre los que se volverá.

42 Programa anticorrupción de ética y cumplimiento para las empresas. Guía práctica, UNODC, 2013, pág. $49 \mathrm{~s}$.

43 En este sentido, de acuerdo con los Comentarios al Convenio de lucha contra la corrupción de funcionarios públicos extranjeros en las transacciones comerciales internacionales, adoptados por la Conferencia Negociadora el 21 de noviembre de 1997, núm. 8: "Sin embargo no habrá delito si la ventaja hubiera sido permitida o requerida por la ley escrita o por reglamentos del país del funcionario público extranjero, incluida la jurisprudencia." 
c) La retribución típica en el tráfico de influencias

Idéntico contenido puede atribuirse a las contraprestaciones que caracterizan al delito de tráfico de influencias (art. 430 CP) a las que se hace mención con las expresiones "dádivas", "presentes" o "cualquier otra "remuneración". El empleo de terminología afín a la empleada en el cohecho disipa cualquier duda acerca de la inclusión tanto de pagos en metálico como en especie, sin que tengan que reiterarse aquí las consideraciones realizadas más arriba respecto de expresiones análogas.

El problema aquí es otro y tiene que ver con la exclusiva tipificación de la venta de influencias, dejando fuera de este concreto tipo la compra de las mismas, sin perjuicio por supuesto de la posibilidad de apreciar la participación en el ejercicio de influencias, cuando proceda.

d) El concepto normativo de donaciones y aportaciones en el delito de financiación ilícita de partidos

En la senda de las anteriores consideraciones, debe decirse que también aquí entran en consideración tanto los pagos en metálico como en especie a los que explícitamente se alude en la Ley de Financiación de los Partidos Políticos -en adelante, LFPP ${ }^{44}$-, art. 2.Dos,c). El problema aquí es el relativo al concepto o título por el que se confieren, pues de todos los pagos que pueden hacerse a los partidos el art. 304 bis CP sólo hace mención a las donaciones o aportaciones, lo que sitúa al intérprete ante un ulterior orden de cuestiones.

En primer lugar, la interpretación del tipo exige una toma de posición previa acerca de la imperatividad de definiciones extrapenales, en torno a la que se enfrentan dos fuerzas interpretativas opuestas. Por un lado, la que aboga por la generalmente reconocida autonomía de los conceptos penales que permite

44 “Artículo 2. Recursos económicos. Los recursos económicos de los partidos políticos estarán constituidos por: (...) Dos. Recursos procedentes de la financiación privada. (...) c) Las donaciones en dinero o en especie (...)."

Estudios Penales y Criminológicos, vol. XXXVIII (extr.) (2018). ISSN $1137-7550$ : 1-58 -22- hitp://dx.doi.org/10.15304/epc.38.5031 
ajustar su contenido a las necesidades tuitivas propias de esta rama del derecho y que aquí llevaría a una definición esencialmente material y extensiva de las contribuciones a los partidos, en línea con lo preceptuado por los instrumentos internaciona$l \mathrm{~s}^{45}$. Por otro lado, la que obliga a inteligir los elementos típicos del delito en sintonía con las definiciones extrapenales, como la mayoría de la doctrina interpreta que debe hacerse aquí, a raíz de la directa remisión del art. 304 bis CP al art. 5 LFPP.

En segundo lugar, de admitirse la relevancia de las definiciones extrapenales, la siguiente cuestión a resolver es la relativa a la concreta identificación y concreción de las que tienen trascendencia para este específico tipo, cuestión que tampoco es incontrovertida, pues no está claro si su objeto se extiende sólo a las donaciones ${ }^{46} \mathrm{o}$ también a las aportaciones ${ }^{47}$, pues no obstante aparecer ambas mencionadas en el art. 304 bis CP, sólo las primeras están recogidas en el art. 5 LFPP $^{48}$. Ello sin perjuicio de que, en su defecto, nada obstaría la posibilidad de recurrir a otros delitos como el cohecho o el tráfico de influencias.

En tercer lugar, deberá resolverse la asimismo discutida cuestión relativa al significado que deba darse a las "donaciones". Por un lado, podría sostenerse un concepto amplio o residual de donación con apoyo en el art. 2.Dos,c)LFPP; por otro, un concepto más estricto derivado de la distinción que el art. 4 LFPP hace entre donaciones y otros conceptos afines.

45 Así, por ejemplo, la Recomendación Rec (2003)4 que, en su artículo 2, define las "donaciones a partidos políticos" desde un punto de vista mucho más material, como "cualquier acto deliberado destinado a conceder ventajas, económicas o de cualquier otro tipo, a un partido político."

46 Las "donaciones" se incluyen entre los "recursos económicos" "procedentes de la financiación privada" [art. 2.Dos, c) LFPP] y se regulan en los arts. 4 y 5 de la misma ley.

47 Las "aportaciones" aparecen también relacionadas en al art. 2, en el que se mencionan tanto las procedentes de los grupos parlamentarios [art. 2.Uno e) LFPP] como las procedentes de los afiliados [art. 2.Dos, a) LFPP].

48 En este sentido, MUÑOZ CUESTA, J.: "La financiación ilegal de partidos políticos. Estado actual de la cuestión. Examen delo nuevo delito de financiación ilegal de partidos políticos", www.fiscal.es. 
Según lo primero, el concepto de donación del art. 2.Dosc) podría acoger cualquiera de los "Recursos procedentes de la financiación privada" no incluidos en el resto de letras del art. 2. Esto es: a) cuotas y aportaciones de los afiliados; b) productos de las actividades propias del partido, o rendimientos procedentes de la gestión de su propio patrimonio; d) fondos procedentes de los préstamos o créditos que concierten; o e) herencias o legados que reciban ${ }^{49}$. En contraste con ello y de acuerdo con el segundo criterio, el concepto de donación podría reducirse a lo incluido en el art. 4. Dos LFPP, que las diferencia no sólo de las aportaciones (que también distingue el art. 2), sino también de las operaciones asimiladas o los acuerdos sobre condiciones de deuda, recogidas en los números Uno, Tres y Cuatro del mismo art. 4 LFPP.

En consecuencia, de acogerse la segunda y más estricta de las acepciones, podrían quedar al margen del tipo supuestos como el alquiler de inmuebles al partido necesitado de liquidez [art. 2.Dos, b) y art. 6 LFPP], el alquiler de estadios para mítines, espacios publicitarios, servicios de mensajería o nóminas ${ }^{50}$ en provecho del partido (art. 4.Tres LFPP) $)^{51}$, o los "acuerdos sobre condiciones de deuda" 52 (art. 4.Cuatro LFPP).

49 Si bien éstas sólo concebibles respecto de personas físicas.

50 Sobre ello, MAROTO CALATAYUD, M.: La financiación ilegal de partidos políticos. Un análisis político criminal, Marcial Pons, Madrid, 2015; NÚÑEZ CASTAÑO, E., "La cuestionable regulación penal de los delitos de financiación ilegal de partidos políticos”, Revista penal, 39/2017. En contra, MUÑOZ CUESTA, J.: "La financiación ilegal de partidos políticos", cit.

51 Práctica por cierto presente en buena parte de los supuestos de FIPP como el "caso Filesa" o "caso Pallerols" en tanto que forma especialmente operativa de ocultación de la financiación al Partido. Al respecto, CUGAT MAURI, M., "La responsabilidad penal de los cargos de los partidos políticos: alternativas típicas y zonas oscuras", en GARCÍA ARÁN y BOTELLA (Dirs.), Responsabilidad jurídica y política de los partidos en España, Tirant lo Blanch, Valencia, 2018.

52 En este sentido, MUÑOZ CUESTA, J., "La financiación ilegal de partidos políticos", cit.; OLAIZOLA NOGALES, I.: "El delito de financiación ilegal 
El absurdo deriva de que, de aceptarse toda esta lista de restricciones podría llegar a considerarse atípico el pago directo del donante al proveedor del partido, mientras que debería reputarse típica la entrega de metálico al partido para que fuera éste quien sufragara de propia mano las deudas con sus proveedores.

Ciertamente, la exclusión de determinadas conductas del ámbito del art. 304 bis CP no impide su subsunción alternativa en otras figuras delictivas ${ }^{53}$, habida cuenta de los más que probables pactos ocultos que puede haber tras las contribuciones de las empresas a los gastos de los partidos $^{54}$. De hecho, ya antes de la expresa tipificación del fenómeno en 2015 se persiguieron algunas de sus manifestaciones ${ }^{55}$. Así, en el caso

de partidos políticos en la reforma del CP”, Diario La Ley, 8516, 10-4-2015, pág.4; GÓMEZ BENÍTEZ, JM.: "Financiación ilegal de partidos políticos y corrupción”, en CASTRO MORENO/OTERO GONZÁLEZ, Prevención y tratamiento punitivo de la corrupción en la contratación pública y privada, Dykinson, 2016, pág. 149.

Sobre el volumen y problema de las condonaciones de deuda en España antes de su prohibición en 2015, véase DE LA NUEZ, E.: "Partidos políticos y transparencia", en NIETO MARTÍN, A./MAROTO CALATAYUD, M. (Dirs.), Public compliance. Prevención de la corrupción en administraciones públicas y partidos políticos, Ediciones de la Universidad de Castilla-la Mancha, Cuenca, 2014, pág. 173. Sobre su importancia en la financiación de los Partidos en España, MAROTO CALATAYUD, M.: La financiación, cit., pág. 39.

53 Así, por ejemplo, según MAROTO CALATAYUD, M.: La financiación ilegal”, cit., pág. 255, la exclusión de las condonaciones de deuda del art. 304 bis CP no impide, en su caso, apreciar otros delitos como, por ejemplo, el cohecho, si es el precio que se paga por la obtención del favor público.

54 El peligro de mercantilización de las donaciones procedentes de las empresas llevó primero a la prohibición de las que procedieran de las contratistas con la Administración (Art. 4. Tres, c) LOFPP 3/1987, 2-7 y Art. 4. Dos, c) LOFPP 8/2007, 4-7), y más recientemente, desde 2015, las de de cualquier persona jurídica (LO 3/2015). A salvo de esta prohibición quedan no obstante las donaciones a las Fundaciones vinculadas a los Partidos (Disp. Ad. $7^{\mathrm{a}}$. LOFPP).

55 Ampliamente, sobre las alternatives típicas en materia de financiación illícita de partidos y corrupción, CUGAT MAURI, M., "La responsabilidad penal de los cargos de los partidos", cit. 
Filesa $^{56}$, que se saldó con la condena por delitos como la apropiación indebida en los supuestos de ausencia de autorización societaria para la disposición patrimonial en favor del partido, fraude fiscal por el cómputo de las donaciones como gastos deducibles en los supuestos de superación del umbral cuantitativo mínimo, falsedad documental por la emisión de facturas por servicios supuestos por parte de las sociedades instrumentales del partido, y el errático delito de asociación ilícita, acerca de cuya aplicabilidad al caso todavía se discute. Más recientemente también, en el caso Palau de la Música (SAP Barcelona 29-12-2017, pendiente todavía de pronunciamiento en casación), resuelto en primera instancia con la condena, entre otros, por el delito de tráfico de influencias, en consideración a la contraprestación que el partido habría recibido a cambio de las gestiones en favor de la contratista.

\subsubsection{Los favores inmateriales y su desigual presencia} en los diversos tipos de delito

De las tipicidades hasta aquí analizadas las únicas que se han modificado tras las Recomendaciones del GRECO en favor de recoger los favores inmateriales como "favores sexuales, títulos honoríficos, pertenencia a alguna red o club social" han sido las del cohecho nacional e internacional ${ }^{57}$. Tales indicaciones están tras la reforma de 2010 por la que se introdujo la expresión

56 En el "caso Filesa" (STS 1/1997, 28-10) los delitos falsarios, sin ser los únicos (además de la apropiación indebida y fraude fiscal), concentraron especial protagonismo. Ante la ausencia de una tipicidad específica de financiación ilegal (aparte de las limitadas tipicidades de la LOREG para el contexto electoral) y a falta de prueba de la conexión causal entre las donaciones al partido y las correlativas desviaciones de la función pública, sólo quedaba la criminalización del fraude en el mecanismo recaudatorio, que aquí consistió en la emisión de facturas por servicios supuestos por parte de sociedades pantalla que por un lado recibían fondos de las empresas donantes y por otro los destinaban a los proveedores del partido. Cuestión distinta es la corrección de la decisión del Tribunal Supremo de calificar la emisión de facturas por servicios supuestos como falsedades materiales punibles, a fin de garantizar la condena de los principales imputados.

$57 \mathrm{Al}$ respecto, véase el Informe de evaluación relativo a España Incriminación (ETS 173 y 191, GPC 2) (Tema 1) Adoptado por el GRECO En su 42 
"favor o retribución de cualquier clase" en las modalidades de cohecho pasivo de los arts. 419 a $421 C P^{58}$. No así del llamado "cohecho de facilitación" que se contrae a la "dádiva o regalo" (art. 422 C) o el cohecho activo que no recoge la expresión "favor" aunque sí "retribución" (art. $424 \mathrm{CP}$ ). En esta línea apuntaría, además, la contemporánea conversión de la antigua pena de multa proporcional al valor de la dádiva en otra calculada según el sistema de días-multa (arts. 419, etc.) ${ }^{59}$, así como la previsión para las personas jurídicas de una pena de multa proporcional alternativa a la de días multa, calculada ahora sobre el beneficio y no la dádiva (art. 427 bis CP) ${ }^{60}$.

Análogas consideraciones merece la reforma del delito de corrupción transnacional del art. 286 ter CP que si bien originariamente sólo recaía sobre "dádivas" y "presentes" ${ }^{61}$, a partir de 2010, se ampliaría a "cualquier beneficio indebido, pecuniario o de otra clase" ${ }^{62}$ y desde 2015 también a las ventajas. Debiendo observarse que, en sintonía con ello, también aquí la reforma de

Reunión Plenaria (Estrasburgo, 11-15 Mayo 2009), Tercera Ronda de evaluación, pár. 92.

58 Aunque para algunos, los favores inmateriales ya estaban incluidos. En este sentido, NAVARRO CARDOSO, F.: "Cohecho pasivo subsiguiente o por recompensa”, Revista electrónica de ciencia penal y criminología, 18-25, 2016, pág. 32 y doctrina allí citada.

La jurisprudencia no había observado hasta la fecha óbice alguno a la inclusión de los servicios de prostitución entre las dádivas propias del cohecho, como así, en la STS 362/2008, 13-6, que estimó que los guardia civiles que utilizaron los servicios de un prostíbulo sin satisfacer precio alguno por los mismos incurrieron en un delito de cohecho de facilitación, previsto y penado al tiempo de los hechos en el art. 426 CP (hoy 422).

59 Así, Informe de evaluación relativo a España del Tercer ciclo de evaluación del GRECO Incriminación (ETS 173 y 191, GPC 2) (Tema 1), 15-5-2009, pár. 21.

60 Así lo observa NAVARRO CARDOSO, F.: "Cohecho pasivo subsiguiente", cit, pág. 32.

61 Con todo, FABIÁN CAPARRÓS, E.: La corrupción de agente público extranjero e internacional, Tirant lo Blanch, Valencia, 2003, pág. 95 s., sobre la situación previa a la reforma se pronunciaba a favor de un concepto amplio del beneficio.

62 Expresión que se ajusta más abiertamente a la literalidad del Convenio OCDE: "beneficio indebido, pecuniario o de otra clase". 
2010 modificó la pena de multa, que dejaría de ser proporcional al valor de la dádiva para pasar a calcularse conforme al sistema de días multa o alternativamente un múltiplo del beneficio (art. 286 ter. $1,2^{\circ}$ pár $\mathrm{CP}$ ), como también se prevé para las personas jurídicas (art. $288 \mathrm{CP}$ ).

Sin embargo, siendo patente la voluntad de cambio del legislador de 2010, plasmada en la modificación terminológica y el renovado sistema de cálculo de la multa, no está tan claro el alcance de la misma. Continúa siendo una cuestión abierta si el objeto del delito se extiende a los favores no monetarizables, por cuanto si bien los instrumentos internacionales invocados instan a la inclusión de contraprestaciones inmateriales ${ }^{63}$ (los "beneficios indebidos" ${ }^{64} \mathrm{o}$ "ventajas indebidas" $\left.{ }^{65}\right)$, los ejemplos que ofrecen sus aparatos interpretativos se concentran en lo que ya podían considerarse pagos en especie, como el sufragio de las vacaciones, la promoción laboral, etc ${ }^{66}$. Constatación que nos

63 La práctica totalidad de instrumentos internacionales se refiere a ellos. Así, según la Guía legislativa para la aplicación de la Convención de las Naciones Unidas contra la Corrupción Segunda edición revisada, 2012, respecto del soborno activo de funcionarios públicos nacionales (pár. 196): "La figura delictiva debe abarcar los casos en que no se ofrezcan ningún regalo ni otro artículo material. De este modo, los beneficios indebidos podrán ser tangibles o intangibles, y tanto pecuniarios como no pecuniarios". Igualmente, el Rapport explicatif de la Convention pénale sur la corruption del Consejo de Europa, Strasbourg, 27.I.1999, art. 2, pár. 37: "Ces avantages indus sont généralement d'ordre économique ou financier ; mais ils peuvent également avoir un caractère non matériel."

64 Arts. 15 y 16 (para el soborno en el sector público) y 18 (para el tráfico de influencias) de la Convención de las Naciones Unidas contra la corrupción, de 2004.

65 Así, Convenio Penal sobre la Corrupción del Consejo de Europa, de 27-11999, arts. 2 al 11 para el cohecho y 12 para el tráfico de influencias.

66 Entre las ventajas a las que se refiere el Programa de acción contra la corrupción del Consejo de Europa GMC (96) 95 cita: los préstamos, viajes, comidas y bebidas de especial valor, promoción laboral, etc. Es decir, lo que tradicionalmente se había recogido bajo el concepto de "pagos en especie". En la misma senda, Rapport explicatif de la Convention pénale sur la corruption del Consejo de Europa, Strasbourg, 27.I.1999, art. 2, pár. 37: "argent, vacances, prêts d'argent, nourriture et boissons, accélération du traitement d'un dossier, meilleures perspectives de carrière, etc." 
lleva a preguntarnos si la razón de ser de la reforma no se hallaba tanto en la resolución de un vacío legal cuanto en la irreflexiva satisfacción de las demandas de actuación de la comunidad internacional, o más en concreto, de las comisiones de evaluación del grado de cumplimiento de los tratados por parte de España, a las que no habrían llegado o convencido los argumentos doctrinales acerca de la suficiencia normativa antecedente, reforzada por la existencia del tipo de abusos sexuales de funcionario del art. $443 \mathrm{CP}$.

Frente a ello, el objeto del delito de tráfico de influencias del art. 430 CP podría estar más acotado, con apoyo en tres órdenes de consideraciones. En primer lugar, las relativas a la literalidad del tipo que no hace referencia a los "favores" - como en el cohecho pasivo de los arts. 419 a 421- sino a "cualquier otra remuneración". En segundo lugar, la ausencia de idénticas reformas en 2010 destinadas a incluir sin lugar a dudas los favores inmateriales ${ }^{67}$. En tercer lugar, porque si ya es discutible que el funcionario competente que solicita o acepta un favor sexual sea sancionable por ello como autor de cohecho, todavía más cuando quien solicita el favor sexual no es ni tan siquiera el funcionario competente sino un tercero y su relación con la desviación de la función es todavía lejana, pues ello podría llevar a una desmesurada intromisión del derecho penal en las razones profundas de las relaciones humanas. Sin embargo, frente a los anteriores argumentos, existen pronunciamientos doctrinales ${ }^{68} \mathrm{y}$ jurisprudenciales (STS 335/2006, 24-369) favorables a una interpretación amplia de la contraprestación típica.

67 Al respecto, véase el Informe de evaluación relativo a España Incriminación (ETS 173 y 191, GPC 2) (Tema 1) Adoptado por el GRECO En su 42 Reunión Plenaria (Estrasburgo, 11-15 Mayo 2009), Tercera Ronda de evaluación, Recomendación 6, pág. 36.

68 DÍAZ MAROTO Y VILLAREJO, J.: "Sobre la práctica del lobby y los delitos de tráfico de influencias", Diario La Ley, núm. 7286, 18-11-2009, D-356, pág. 1486.

69 La sentencia se pronuncia sobre un caso en el que lo solicitado para ejercer la influencia era la colocación laboral de la mujer, a propósito de lo que se 
Por fin, los favores inmateriales quedan abiertamente al margen del delito de financiación de partidos del art. 304 bis CP para el que el contenido económico de las donaciones y aportaciones es consustancial al objeto de la ley de remisión -la Ley de financiación de partidos políticos-.

En suma, las tipicidades que podrían acoger más holgadamente los favores inmateriales como los sexuales son el cohecho pasivo y la corrupción internacional (activa). Por el contrario, es dudoso que puedan ser objeto del cohecho activo, en el que no se menciona a los "favores"; podría discutirse respecto del tráfico de influencias (pasivo), en el caso de los favores sexuales, so pena de una excesiva intromisión de los motivos profundos de las relaciones humanas; y quedan claramente fuera del delito de financiación ilícita por la propia naturaleza de las contribuciones -donaciones y aportaciones definidas en la LFPP- que están en su punto de mira.

De todas, la única tipicidad de la que podría responder la empresa por el ofrecimiento de favores inmateriales sería la de corrupción transnacional (art. 286 ter CP). Paradójicamente, por esta vía, una empresa podría incluso responder por la relación sexual cometida en su nombre y beneficio, lo que nos lleva a pensar que si por lo general no se contempla la responsabilidad penal de las empresas por los delitos sexuales que puedan cometer sus empleados no es por un obstáculo ontológico, sino simplemente porque en principio no se realizan "en beneficio" de la empresa, a diferencia de lo que ocurre cuando la relación sexual tiene un carácter instrumental para la conquista de posiciones en el mercado (y en concreto, el internacional).

extiende sobre la amplitud que a su juicio debe otorgarse a la contraprestaci'n propia del tráfico de influencias: "dentro de estos términos no se menciona el aspecto económico, aunque usualmente será esa contraprestación la que actúe, pero la amplitud de la frase «cualquier otra remuneración» permite interpretar los términos del precepto de tal suerte que en el concepto puede comprenderse cualquier recompensa o beneficio del tipo que sea." 


\section{La orientación subjetiva del favor}

Todos los delitos hasta aquí analizados, con la única excepción de la financiación ilícita de partidos se caracterizan por la presencia de un elemento subjetivo del injusto o intención subjetiva trascendente que confieren al pago ofrecido o realizado significado penal a partir del fin o motivo por el que se satisface.

El problema que presentan estos elementos, como siempre, es de prueba, y para las compliance, de detección o prevención anticipada.

\subsection{El elemento subjetivo del injusto y su difícil plas- mación en los códigos de actuación empresarial}

Ninguna duda cabe acerca de que la intención con la que se ofrece o solicita el favor o retribución es un elemento subjetivo determinante de la existencia del delito de cohecho ${ }^{70}$, como también de su concreta naturaleza y gravedad, que variarán en función de si se orienta o no a la retribución de un concreto hecho y en su caso, si es pasado, futuro o contrario a las obligaciones del cargo. Ello nos sitúa ante un delito para cuya consumación no se requiere de la ejecución de ninguna de las partes del pacto corrupto ${ }^{71}$. De hecho, salvo en la modalidad del art. 422 $\mathrm{CP}$-que exige que el funcionario admita la propuesta del particular-, se discute incluso si es preciso que la oferta sea idónea

70 Así, STS 636/2006, 8-6 o STJ Andalucía: STJ 6/2007 de 20 de marzo 2007.

71 Guía legislativa para la aplicación de la Convención de las Naciones Unidas contra la Corrupción Segunda edición revisada, 2012, pár. 198: "se debe establecer algún nexo entre el ofrecimiento o el beneficio y la inducción al funcionario a que actúe o se abstenga de actuar en cumplimiento de sus funciones oficiales. Como la conducta abarca los casos en que meramente se ofrece un soborno, es decir, también aquellos en que no se acepta, y que por ello no puede incidir en el comportamiento, el nexo debe ser que el acusado intente no solo ofrecer el soborno, sino también influir en la conducta del receptor, con independencia de si lo logra o no". 
para convencer a la contraparte ${ }^{72}$, aunque reine general consenso acerca de que debe revestir una entidad cuantitativa mínima ${ }^{73}$.

Sin embargo, en la práctica, es difícil castigar el cohecho antecedente cuando no se llega a conseguir la actuación pública a la que apunta la dirección final del pago $^{74}$ o cuando consiste en un acto propio del cargo que de todos modos hubiera podido adoptarse ${ }^{75}$-sobre la atipicidad de actos debidos, véanse las

72 En contra de exigir la idoneidad de la oferta, respecto del art. 268 ter CP, GALÁN MUÑOZ, A.: "Globalización, Corrupción internacional y Derecho penal. Una primera aproximación a la regulación penal de dicho fenómeno criminal tras la LO 1/2015", Estudios penales y criminológicos, núm. 36, 2016, pág. 639.

73 Así, vid supra, GÓMEZ RIVERO, C.: "Derecho penal y corrupción", cit.; respecto del delito de corrupción en las transacciones comerciales internacionales, FABIÁN CAPARRÓS, E.: La corrupción de agente público, cit., pág. $95 \mathrm{~s}$, que considera desechables los pequeños regalos como flores, bombones, objetos publicitarios, gratificaciones, etc., si bien recordando la llamada que hace el Convenio OCDE a las normas y usos locales a fin de afirmar la tipicidad del hecho.

$74 \mathrm{Al}$ respecto, de especial interés son las observaciones de GÓRRIZ ROYO, E.: "Corrupción urbanística: análisis criminológico y respuestas jurídicopenales", en JAREÑO LEAL, A (DIR.): Corrupción pública: cuestiones de política criminal", iustel, Madrid, 2014, pág. 131 s. sobre el "Caso Malaya" (SAP Málaga 535/2013, 4-10), en que no obstante el grado de corrupción reinante en el Ayuntamiento de Marbella, determinante de su disolución, no se pudo llegar a establecer la relación causal entre los pagos a los funcionarios "en nómina" del intermediario (Sr Roca) y cada uno de los actos realizados, por lo que se condenó por el delito del art. $420 \mathrm{CP}$, primer inciso de la versión anterior a la reforma de 2010, para el que no se requiere de la ejecución del concreto acto.

75 Supuestos en los que no queda excluida la relevancia penal de la conducta. Así, respecto del cohecho impropio, VÁZQUEZ-PORTOMEÑE SEIJAS, F.:

"El tráfico de influencias y su criminalización en el contexto internacional", Diritto penale contemporáneo, 2015; respecto del delito de corrupción en las transacciones comerciales internacionales, GALÁN MUÑOZ, A.: "Globalización", cit, pág. 635, llamando la atención acerca de la supresión de la exigencia de que el contrato o beneficio conseguido sea "irregular" como preveía el tipo originario del art. $445 \mathrm{CP}$, no ya el actual art. 286 ter CP. En los Comentarios al Convenio de lucha contra la corrupción de funcionarios públicos extranjeros en las transacciones comerciales internacionales, adoptados por la Conferencia Negociadora el 21 de 
“excepciones" previstas en la Foreign Corrupt Practices Act ${ }^{76}$ por pagos por actos rutinarios que en todo caso se hubieren realizado $^{77}-$.

En otros países estas dificultades se han intentado sortear a través de figuras como la del enriquecimiento injustificado de funcionarios que permite prescindir de la prueba del nexo causal entre el pago y el acto de desviación de la función. En el nuestro, se afrontan en parte a través del cohecho subsiguiente que permite perseguir supuestos de cohecho antecedente respecto de los que no se puede probar el pacto previo $^{78} \mathrm{o}$ el cohecho de facilitación.

Las anteriores consideraciones son trasladables al delito de tráfico de influencias que también encierra un pacto de futuro y teóricamente se consuma con independencia de que se lleve a cabo la contraprestación prometida e incluso, según la alguna sentencia, ante influencias supuestas (STS 1335/2001, 19-7). Otra cosa es que raramente se castigue cuando no se alcanza ${ }^{79}$.

noviembre de 1997, se advierte que las ventajas indebidas comprenden los casos en que la empresa involucrada resultaba ser idónea o incluso la mejor capacitada. Interpretación a la que por otro lado alude la Guía legislativa para la aplicación de la Convención de las Naciones Unidas contra la Corrupción Segunda edición revisada, 2012, pár. 213, nota 25, en su comentario al significado de la expresión "beneficio indebido".

76 A diferenciar de las Affirmative defenses, reguladas en el " $\$ 78 d d-1$ [Section 30A of the Securities \& Exchange Act of 1934]. Prohibited foreign trade practices by issuers (c).

77 " $\$$ 78dd-1 [Section 30A of the Securities \& Exchange Act of 1934]. Prohibited foreign trade practices by issuers (b) Exception for routine governmental action Subsections (a) and (g) of this section shall not apply to any facilitating or expediting payment to a foreign official, political party, or party official the purpose of which is to expedite or to secure the performance of a routine governmental action by a foreign official, political party, or party official."

78 Sobre las distintas interpretaciones doctrinales acerca de los supuestos a los que podría ser aplicable, NAVARRO CARDOSO, F.: "Cohecho pasivo subsiguiente", cit., pág. 18.

79 Problema similar al que se plantea, en sede de tráfico de influencias, respecto del problema de prueba de la relación de causalidad entre la influencia y la 
No sucede lo mismo con el delito de financiación ilícita de partidos, desprovisto de especiales elementos subjetivos como no sea en la modalidad de la donación finalista prevista en el art. 5.Uno, a) LFPP al que se remite el art. 304 bis CP. Es más, si como se afirma este tipo puede cumplir una función supletoria de los delitos contra la función pública es precisamente porque puede aplicarse con abstracción de la prueba del verdadero motivo de la donación y su conexión final con la actuación pública esperada.

En contraste con la relevancia del componente subjetivo en los anteriores delitos -cohecho y tráfico de influencias-, las pautas de conducta sobre las que pueden tener control las empresas son esencialmente objetivas o materiales. Así, por ejemplo, la prohibición de disposiciones en metálico en países de alto riesgo o la obligación de doble firma. A lo sumo, los códigos de conducta pueden instruir a sus destinatarios para que no orienten los pagos en determinada dirección ${ }^{80} \mathrm{y}$ hasta pueden reforzar el mensaje con información más o menos prolija acerca de las consecuencias penales a las que de otro modo se arriesgan unos $\mathrm{y}$ otros. Ahora bien, fuera de su alcance queda la supervisión y control de ánimos e intencionalidades a los que en el mejor de

resolución, determinante de su notable falta de aplicación. Aspecto sobre el que en su día traté en "El tráfico de influencias: un tipo prescindible", Revista Electrónica de Ciencia Penal y Criminología, 2014.

80 Sólo a modo de ejemplo, véase las reglas de conducta elaboradas por OCDE, UNODC, BANCO MUNDIAL, Ética Anticorrupción y Elementos de Cumplimiento Manual para Empresas, 2013. Sólo a título de ejemplo, pág. 38: "Principios PACI para contrarrestar el soborno: 4.2 Contribuciones políticas 4.2.1 La empresa, sus empleados o intermediarios no deben efectuar contribuciones directas ni indirectas a partidos, funcionarios de partidos ni candidatos políticos, ni a organizaciones o individuos dedicados a la política, como subterfugio para encubrir sobornos. (...) 4.3 Aportes a la beneficencia y patrocinios 4.3.1 La empresa debe asegurar que los aportes otorgados con fines de beneficencia y patrocinios no sean utilizados como subterfugio para encubrir sobornos. (...) 4.5 Regalos, hospitalidad y gastos 4.5.1 La empresa debe prohibir el ofrecimiento de regalos, hospitalidad y gastos cuando estos puedan afectar indebidamente, o puedan ser percibidos como capaces de afectar el resultado de una adquisición u otra operación comercial y no sean gastos razonables de buena fe. (...)." 
los casos sólo podrá llegarse por la vía de la información, formación o sensibilización ${ }^{81}$.

Por ese motivo difícilmente una compliance podrá erradicar completamente las posibilidades de delito, pues bastará con que ese inaprehensible elemento subjetivo esté presente en uno de los actos permitidos para que reaparezca el peligro. Así por ejemplo, en caso de pactum sceleris entre quien debe autorizar un acto de disposición y quien lo ejecuta o entre quienes están llamados a la doble firma.

Ante ello, una empresa precavida podría plantearse prohibir cualquier pago a toda persona directa o indirectamente relacionada con el funcionario a fin de eliminar de raíz la posibilidad de que se concediera con el ánimo subjetivo propio del delito. Ahora bien, ello además de infructuoso podría ser excesivo. Infructuoso porque solo alcanzaría los supuestos de conflictos de interés detectables ex ante (por ejemplo, por razón de parentesco), dejando fuera otros que también pueden surgir (por ejemplo, si el interés apareciera respecto de alguien excluido de los motivos de abstención o recusación como puede ser el contratista con el que habitualmente trata el funcionario ${ }^{82}$ ). Además, podría ser excesivo si se hiciera a costa de una restricción desproporcionada de las posibilidades de desarrollo profesional o empresarial de cuantos pudieran tener alguna relación con el funcionario, vetando las posibilidades de relación comercial o laboral además de con los parientes, también con sus amigos y respectivos parientes, etc., en una cadena interminable de afectados. Nadie niega que, eventualmente el funcionario puede

81 Sobre la importancia de estas campañas, véase OFICINA ANTIFRAU DE CATALUNYA, La gestió dels conflictes d'interès en el sector públic de Catalunya, Barcelona, 2016, págs. 56 ss.

82 Sobre los límites de la abstención y la recusación ante relaciones nacidas al calor de las relaciones profesionales, véase OFICINA ANTIFRAU DE CATALUNYA, La gestió dels conflictes d'interès en el sector públic de Catalunya, Barcelona, 2016, pág. 88, que frente al riesgo derivado del contacto duradero entre funcionarios y contratistas propone un sistema de rotaciones periódicas y obligatorias. 
verse influido por las peticiones del amigo del amigo del familiar. Ahora bien, para cuando eso suceda ya está el tráfico de influencias, que admite su comisión "en cadena", superando los tradicionales obstáculos al veto de la participación en la participación.

Dicho todo lo anterior acerca del peso de la intención en la calificación penal del pago no puede olvidarse que el umbral mínimo del delito ${ }^{83}$ viene determinado por el criterio de la insignificancia ${ }^{84}$, que por resbaladizo que sea ${ }^{85}$ no puede quedar anulado por la mera presencia del ánimo corrupto. De acuerdo con ello, si el pago es irrelevante no habrá delito por mucho que se hubiera ofrecido con ánimo de ganar la voluntad ajena. Gráficamente, pagar un café ${ }^{86}$ al funcionario con competencias de interés para la empresa no puede castigarse como pago corrupto por mucho que se haga con la intención de influir en su voluntad y así se reciba pues sería una subjetivización extrema del contenido de injusto.

En todo caso, ante las dificultades de prueba del elemento subjetivo y la imposibilidad de aprehenderlo por medio de las

83 Sobre la posible fluctuación de ese límite mínimo en función del tipo de delito, véanse las consideraciones de GÓMEZ RIVERO, C.: "Derecho penal y corrupción", pág. 286, acerca de la irrelevancia de un pago de 30 Euros, en especial, tras la conclusión de la actuación funcionarial, a propósito de la SAP de Santa Cruz de Tenerife de 3 de junio de 2011.

84 Al respecto, ampliamente, GÓMEZ RIVERO, C.: "Derecho penal y corrupción", cit.. También, NAVARRO CARDOSO, F.: "Cohecho pasivo subsiguiente, cit, pág. 32. Respecto del delito de corrupción internacional, FABIÁN CAPARRÓS, E.: La corrupción de agente público, cit., pág. 95 s., según el que el beneficio debe tener capacidad de influencia sobre la actuación del funcionario.

85 En este sentido, el Rapport explicatif de la Convention pénale sur la corruption del Consejo de Europa, Strasbourg, 27.I.1999, art. 2, pár. 38: "Pour les auteurs de la Convention, l'adjectif «indu» vise à exclure les avantages qui sont admis par la loi ou par les règlements administratifs, ainsi que les cadeaux de faible valeur ou les cadeaux socialement acceptables."

86 Sobre la tipicidad de ofrecimiento de unas botellas de vino al examinador, STS 513/2008 de 23 de julio 2008. 
compliance, para la prevención del delito se revelan especialmente útiles algunas medidas que llevan a la autocontención como las obligaciones contables ${ }^{87} \mathrm{o}$ en general todas las que favorecen la trazabilidad del pago y la transparencia, que varía en función de la naturaleza de la mercantil o de los fondos que maneje ${ }^{88}$.

Al margen de las anteriores consideraciones queda el delito de financiación ilícita de partidos que, como ya se ha dicho, no contiene especiales elementos subjetivos del injusto. En consecuencia, las pautas que deban adoptar las personas jurídicas son aquí mucho más claras y se resumen en la total prohibición de donaciones a los partidos, como impone la LFPP desde $2015^{89}$. A esa prohibición escapan las donaciones a las Fundaciones de los partidos. Éstas ni se cuentan entre los destinatarios de la financiación delictiva descrita en el art. 304 bis CP ni les alcanzan las prohibiciones de los aps. b) y c) del art. 5.Uno LOFPP al que se remite el CP, en virtud de la excepción contenida en la Disp. Ad. Séptima.Cuatro LOFPP. Por lo tanto, quedan al margen del tipo penal. Otra cosa es que también éstas están suje-

87 Respecto de los partidos, por ejemplo, arts. 14 ss. LFPP; arts. 121 ss. y cc. LOREG.

88 Sobre la diferencia entre la obligación de transparencia (activa) y derecho a la información (pasivo) y su exigibilidad respecto de las distintas clases de empresa, véase GUICHOT, E.: "La nueva regulación legal de la transparencia, el acceso a la información pública y el buen gobierno como mecanismo de lucha contra la corrupción y regeneración democrática", en JAREÑO LEAL, a (DIR.), Corrupción pública: cuestiones de política criminal”, iustel, Madrid, 2014, págs. 215 ss. Sobre las recomendaciones del Consejo de Europa, véase el Informe de evaluación sobre Transparencia en la financiación de partidos políticos en España (Tema 2) Adoptado por el GRECO En su 42 Reunión Plenaria (Estrasburgo, 11-15 Mayo 2009), Tercera Ronda de evaluación, párfs. 73 ss.

89 Hasta la LO 3/2015, 30-3, se habían prohibido en la medida en que la empresa tuviera naturaleza pública $\mathrm{o}$, mediante contrato vigente, prestara servicios o realizara obras o suministros para alguna Administración Pública; y desde la Ley Orgánica 8/2007, de 4 de julio, sobre financiación de los partidos políticos, modificada por LO 5/2012, 22-10 también otras de su entorno como las participadas mayoritariamente por aquellas y sus fundaciones. 
tas a la regulación administrativa ${ }^{90}$ que también puede tenerse en cuenta en el diseño de las compliances. Aun así, si la donación a la Fundación tuviera como objeto su ulterior entrega al Partido ${ }^{91}$ no habría motivo para dejar la conducta fuera del tipo que, según el ap. 4 del art. 304 bis CP, puede realizarse por sí o por persona interpuesta ${ }^{92}$.

\subsection{La dirección final de las contribuciones filantró- picas, esponsorizaciones y ofertas de colocación o promoción laboral}

Como advierten los textos internacionales, el peligro de corrupción puede aparecer tras aportaciones tan aparentemente inocuas e incuestionables como los patrocinios o contribuciones filantrópicas a los que ya se ha hecho mención ${ }^{93}$. Práctica cada

90 Así, según la Disp. Ad. Séptima. Cuatro "En el caso de las donaciones, estarán sometidas a los límites y requisitos previstos en el capítulo segundo del título II, si bien, no será de aplicación lo previsto en el artículo 5.Uno, letras b) y c)." Es decir, no podrán ser : "anónimas, finalistas o revocables", aunque puedan ser superiores a 50.000 euros anuales y proceder de personas jurídicas. Además, según la mismo Disp. Ad. Séptima. Cuatro: "Las donaciones procedentes de personas jurídicas requerirán siempre acuerdo adoptado en debida forma por el órgano o representante competente al efecto, haciendo constar de forma expresa el cumplimiento de las previsiones de la presente ley. Cuando estas donaciones sean de carácter monetario de importe superior a 120.000 euros, tendrán que formalizarse en documento público."

91 Acerca del peligro de financiación de partidos a través de sus Fundaciones políticas, véase el Informe de evaluación sobre Transparencia en la financiación de partidos políticos en España (Tema 2) Adoptado por el GRECO En su 42 Reunión Plenaria (Estrasburgo, 11-15 Mayo 2009), Tercera Ronda de evaluación, pár. 71, según el que, por medio de las donaciones a Fundaciones es posible burlar la regulación sobre financiación de Partidos y alimentar el "pay-to-play". Críticamente también NUÑEZ CASTAÑO, E.: "La cuestionable regulación penal"; cit, pág. 142, y GÓMEZ BENÍTEZ, JM.: "Financiación ilegal de partidos", cit., pág. 148.

92 Sobre la posibilidad de recepción de la donación a través de intermediarios, NUÑEZ CASTAÑO, E.: "La cuestionable regulación penal", cit, pág.141; y GÓMEZ BENÍTEZ, JM.: "Financiación ilegal”, cit, pág.149.

93 Como así advierte el Programa anticorrupción de ética y cumplimiento para las empresas. Guía práctica, UNODC, 2013, pág. 36, que señala que 
vez más difundida como estrategia de definición y comunicación de la identidad corporativa, que puede pasar por la vinculación de la propia firma o marca con determinadas causas y que puede ir desde las campañas de sensibilización hacia un problema social (recuérdense las pioneras campañas de Benetton sobre el SIDA o la anorexia) hasta la canalización de fondos o prestación de servicios en favor de asociaciones sin ánimo de lucro a través de campañas de crowfunding o "teaming" como se ha hecho mención más arriba.

En estos casos, cuando la contribución a determinada política social pasa por el directo beneficio a una concreta persona o entidad cultural pueden saltar las alarmas de riesgo de corrupción si se percibe especial afinidad entre ésta y el funcionario ${ }^{94}$, aunque como también se ha dicho, no pueda afirmarse mecánicamente su relevancia penal, que puede quedar excluida si el

las cuotas de las sociedades filantrópicas deberán considerarse donaciones, doc. cit, pág. 49.

94 Ejemplos de casos en los que se ha pronunciado la autoridad americana responsable del cumplimiento de la Foreign Corrupt Practices Act se hallan en: https://www.justice.gov/criminal-fraud/opinion-releases-index que son de especial interés para nosotros por cuanto, prácticamente no contamos con jurisprudencia sobre el delito de corrupción transnacional en torno al que se plantean los problemas aplicativos que deben tener en cuenta las empresas exportadoras (SAN 3/2017, 23-2). Entre ellos: Foreign Corrupt Practices Act Review Procedure Release No. 80-01 Date October 29, 1980, en el que no se aprecia riesgo de violación de la FCPA en un supuesto en que la empresa estadounidense consultante proyectaba sufragar los gastos educativos del hijo adoptivo de un funcionario con un cargo meramente honorífico en el país extranjero, e hijo natural de otros sin competencias en materias de interés para la empresa, en consideración a la falta de evidencias del posible destino del pago a influir sobre la actuación de la Administración pública extranjera; Foreign Corrupt Practices Act Review Opinion Procedure Release No. 95-01 Date: January 11, 1995, en la que tampoco se percibe riesgo de vulneración de la FCPA en un supuesto en que la empresa que proyectaba construir una planta empresarial en el extranjero se proponía donar una cantidad para la construcción de un complejo hospitalario que debería situarse en las inmediaciones del futuro complejo empresarial, a través de una organización caritativa americana y una sociedad mercantil local, subrayándose que los miembros de estas entidades no trabajaban al servicio de la Administración pública local y que se efectuaría seguimiento del destino de los fondos; idem 
funcionario no tiene competencias en las concretas materias de interés de la empresa o cuando el pago lo realiza el miembro de la empresa a título personal. Al margen quedarían las donaciones en beneficio de la propia Administración ${ }^{95}$ o las actuaciones en interés de ésta ${ }^{96}$.

No. 97-02 Date: November 5, 1997, en que se niega la relevancia del supuesto a ojos de la FCPA, a la vista de que la donación que se iba a destinar a sufragar los gastos de infraestructura de un complejo educativo se ofrecía directamente a la Administración extranjera y no a alguno de sus miembros; idem, No.: 06-01 Date: October 16, 2006, también descarta el peligro respecto de la propuesta de aportar fondos al Gobierno de un país africano para el refuerzo de los controles estatales sobre las mercancía de contrabando; ídem, No.: 1002 Date: July 16, 2010; idem. No.: 09-01 Date: August 3, 2009, también descarta el riesgo por cuanto la aportación de material médico tenía como destinataria a la Administración, siendo seleccionados los centros receptores en función de criterios objetivos; ídem, No.: 10-02 Date: July 16, 2010, sobre la consulta elevada por una entidad americana sin ánimo de lucro dedicada a la concesión de microcréditos a empresas con recursos escasos, una de cuyas filiales preveía acompañar su transformación en entidad mercantil de la contribución a financiera a otra entidad local igualmente dedicada a los microcréditos. También en este supuesto la Autoridad americana concluye la ausencia de riesgo de corrupción, pues a pesar de que la donación se realiza con el fin de desarrollar la propia actividad empresarial en el extranjero, se establecen controles suficientes para evitar que se desvíe para el enriquecimiento personal de concretos funcionarios; ídem, No. 13-01 Date: December 19, 2013, en que no se aprecia riesgo de violación en un supuesto en que el abogado al servicio de una compañía que prestaba asistencia legal a un gobierno extranjero se proponía sufragar los gastos médicos de la hija de un funcionario, por cuanto ninguno de los dos tenía competencias decisorias sobre el mantenimiento de la relación comercial, y se ofrecía suficientes garantías de no violación.

En suma, la alerta de peligro salta cuando el pago puede beneficiar al funcionario competente o alguien de su círculo. De acuerdo con ello, se descarta el riesgo cuando no se aprecia la posible relación del pago con ninguno de estos sujetos, sea porque se ofrece directamente a la Administración y no a un concreto miembro de la misma, sea porque, ofreciéndose a un particular no guarda relación con el funcionario competente ni directa ni indirectamente a través de familiares o allegados.

95 Así, SAP Valencia 550/1997, 2-12, que absuelve al Alcalde que propuso a la empresa explotadora de unas canteras que sufragaran el coste del camino hasta las mismas, por ser de casi exclusivo uso de aquélla.

96 Criterio a tener en cuenta también en la valoración de la concurrencia del delito de malversación, así, STS 927/2003, 23-6. Con todo, en línea con las 
En supuestos así la calificación jurídico penal pasa por el esclarecimiento de dos cuestiones. En primer lugar, la correspondencia entre la ayuda prestada y el contenido propio de los diversos delitos, que como ya hemos visto no plantea óbices a los pagos en favor de entes sin ánimo de lucro o a título de esponsorización. En segundo lugar, la prueba del elemento subjetivo propio de cada uno de ellos y su difícil encaje en los códigos de conducta empresariales, de lo que se trata a continuación.

Desde el punto de vista de las compliances, el problema radica en que, si bien puede prohibirse el pago a entidades benéficas cuando así lo haya exigido el funcionario competente o quien pueda influir sobre él, no puede prohibirse sin más ${ }^{97}$. Por lo tan-

observaciones de JAREÑO LEAL, A.: "La corrupción en la contratación pública", en JAREÑO LEAL, a (DIR.), Corrupción pública: cuestiones de política criminal”, iustel, Madrid, 2014, pág. 154, del hecho de que una concreta actuación no beneficie a un funcionario en particular no puede derivarse el beneficio para la Administración ni la ausencia de relevancia penal de la conducta, pues delitos como la prevaricación no exigen tal componente lucrativo.

97 Y ahí, precisamente, estriba el nudo y obstáculo a la prueba del delito que, como advierte la Guía legislativa para la aplicación de la Convención de las Naciones Unidas contra la Corrupción, Segunda edición revisada, 2012, pág. 41, obliga a distinguir entre diversas hipótesis: Prácticas comerciales que son ilícitas pero que son percibidas como normales e incluso requeridas (v. gr., los pagos de facilitación); Prácticas comerciales que son legales pero que implican el riesgo de ser utilizadas para encubrir la corrupción (v. gr., mala utilización de las contribuciones políticas, regalos u hospitalidad como sobornos para un funcionario público nacional); y Prácticas comerciales basadas en decisiones sesgadas (conflictos de intereses).

En este sentido, Programa anticorrupción de ética y cumplimiento para las empresas. Guía práctica, UNODC, 2013, pág. 41: "No todas las actividades son tan claras como sobornar a un funcionario público para ganar un contrato. Sin embargo, es especialmente dificil en los casos en los que la frontera entre las prácticas legales y las corruptas está difuminada. Por ejemplo, aunque en algunos medios es una práctica común y permitida el ofrecer regalos para mantener buenas relaciones comerciales, los regalos que influyen en una decisión están estrictamente prohibidos. Por ende, pueden existir muchas áreas grises. Algunos casos pueden de hecho constituir un acto de corrupción pero no ser percibidos como tal." Así mismo, op. cit., pág. $46 \mathrm{~s}$. 
to, habrá supuestos que sólo se tiñan de ilicitud en consideración al motivo o intención que los anime ${ }^{98}$, que como ya se ha dicho ni la más impoluta guía de conducta ${ }^{99}$ podría prevenir de modo absoluto $^{100}$, en especial, cuando el círculo de personas físicas o jurídicas en las que puede tener interés el funcionario o que puedan influir sobre él es tan amplio que una medida muy exigente a buen seguro desembocaría en resultados desproporcionados.

98 En este sentido, véase en especial, las consideraciones vertidas en la Foreign Corrupt Practices Act Review Opinion Procedure Release, No. 13-01 Date: December 19, 2013, ya citada, de acuerdo con la cual, el hecho de financiar los gastos médicos del familiar del funcionario podría o no infringir la FCPA en función de si con ello se pretendiera influir en la actuación del funcionario competente. Motivo por el cual, en el caso sometido a su consideración no se apreció vulneración de la referida ley, pero sí en otros como el enjuiciado en Liebo, 923 F.2d at 1311, en el que se condenó a quien sufragó gastos personales y viajes del amigo y primo del funcionario con el intento de influir sobre la adquisición o conservación de negocios que de otro modo no se habrían conseguido.

La presencia del elemento subjetivo puede por lo tanto hacer que el más mínimo pago se tiña de ilícitud. En este sentido se entiende que en los Comentarios al Convenio de lucha contra la corrupción de funcionarios públicos extranjeros en las transacciones comerciales internacionales, adoptados por la Conferencia Negociadora el 21 de noviembre de 1997, núm. 7 , se hable de la relevancia del mismo con independencia de la cuantía: "7. Constituye asimismo un delito independientemente, entre otras cosas, del valor de la ventaja o de su resultado."

99 Entre las posibles pautas, el Programa anticorrupción de ética y cumplimiento para las empresas. Guía práctica, UNODC, 2013, pág. 47 cita el establecimiento de límites claros respecto de: “• Los tipos de regalos, hospitalidad, modos de viaje o tipos de entretenimiento que son aceptables; - Los límites de su valor monetario; $・$ El reembolso por la contraparte; • Las características de la contraparte; • La naturaleza de la relación comercial; $y$ •La ocasión. ", así como formas de reducir la inseguridad respecto de tales límites por la vía de la definición de: "procedimientos de aprobación (v. gr., aprobaciones múltiples para los beneficios que involucren a funcionarios públicos), responsabilidades definidas (v. gr., a quién se tiene que informar) y requisitos de documentación (v. gr., qué se tiene que registrar)."

100 Este es el motivo por el que un sistema de certificación preventiva de la inexistencia de riesgos en determinada práctica como el que contempla el sistema de aplicación de la FCPA americana podría facilitar el desarrollo normal de la actividad económica que de otro modo puede verse sometida a excesivas restricciones ex ante sin que siempre haya motivo para ello. 
Las mismas consideraciones cabe hacer sobre los supuestos de contratación o esponsorización de familiares o empresas cercanas al funcionario ${ }^{101}$. No me refiero aquí a los supuestos en que el negocio jurídico no es tal sino patente camuflaje de donaciones encubiertas sobre cuya irregularidad no existen dudas, sino a aquellos en que el familiar o su empresa ofrecen efectivamente las prestaciones que son objeto de contrato.

En tales supuestos, ante la insatisfacción que produce la incontinente ampliación de la lista de incompatibilidades, podría recurrirse al principio "cumplir o explicar" 102 que permite flexibilizar las pautas de conducta a la luz de criterios de racionalidad económica.

\subsection{El doble elemento subjetivo del injusto en la corrupción de empresa}

Para afirmar la responsabilidad penal de las personas jurídicas por los delitos de corrupción será preciso afirmar, junto al elemento subjetivo propio de cada figura penal, otro más, cual es la actuación en su beneficio directo o indirecto, tal como prevé el art. 31 bis $\mathrm{CP}^{103}$. Sin ese requisito faltaría una de las condiciones para afirmar el hecho de conexión en el que se basa la res-

101 Así, DÍAZ MAROTO Y VILLAREJO, J.: "Sobre la práctica del lobby”; cit., pág. 1487, considerando, a propósito del delito de tráfico de influencias, que hoy en día el solo hecho de disponer de un contrato laboral es un valor en sí mismo considerado. En este sentido, STS 335/2006, 24-3, en el que el hijo del Presidente de la Diputación ofrecía sus influencias familiares a cambio de que contrataran a su esposa, como así consiguió.

102 Art. 20 de la Directiva 2013/34/UE; art. 540.4, g) Real Decreto Legislativo $1 / 2010$, de 2 de julio, por el que se aprueba el texto refundido de la Ley de Sociedades de Capital; CNMV, Código de buen gobierno de las sociedades cotizadas, CNMV, febrero, 2015 y CNMV, Guía técnica de buenas prácticas para la aplicación del principio «cumplir o explicar», 15-7-2016.

103 Esa es también la idea que subyace a la exclusión de la apropiación indebida o administración desleal de la lista de delitos de los que puede responder una persona jurídica, que en principio será la perjudicada por lo que haga la persona física. 
ponsabilidad corporativa. Ahora bien, no basta con ello. Además, es preciso afirmar la falta de voluntad de la empresa en impedir el delito $^{104}$.

Este planteamiento presupone que pueden cometerse delitos en beneficio (objetivo) de la empresa pero en contra de su "voluntad", o más propiamente, "eludiendo fraudulentamente los modelos de organización y prevención" (art. 31 bis.2, $3^{\mathrm{a}} \mathrm{CP}$ ).

Desde este punto de vista, podría hablarse de la exigencia de un doble elemento subjetivo y con ello también de un doble problema de prueba. Por un lado, el que plantean elementos subjetivos del delito; por otro, el que obliga a valorar el grado de control y compromiso efectivo de la empresa con el programa de cumplimiento y el correlativo esfuerzo que la persona física haya debido emplear para sortear las medidas de prevención del delito.

\section{Sujetos expuestos al riesgo de corrupción}

Lógicamente, en el punto de mira de las reglas de conducta sobre pagos y atenciones de las empresas estarán los funcionarios competentes para actuar en favor de la empresa. Sin embargo, no son los únicos que deberán ser tomados en consideración por las compliance que también deberán evitar pagos a terceros cuando actúen como lunga mano del funcionario, sean beneficiarios de sus favores o puedan influir sobre

104 Como resumen VILLEGAS GARCÍA, MA., ENCINAR DEL POZO, MA., "La responsabilidad penal de las personas jurídicas. La Jurisprudencia de la Sala de lo Penal del Tribunal Supremo", Diario La Ley, 26-12-2017, pág. 1: "No basta, para la condena de la persona jurídica, la constatación de la comisión de un delito por parte de la persona física - en nombre $y$ en beneficio directo o indirecto de aquella - sino que será preciso la indagación sobre aquellos elementos organizativo-estructurales de la entidad que han posibilitado un déficit de los mecanismos de control y gestión, con influencia decisiva en la relajación de los sistemas preventivos llamados a evitar la criminalidad en la empresa". 
su voluntad. El problema está en la delimitación de ese círculo de sujetos ${ }^{105}$.

a) Funcionarios, concesionarios y otros sujetos con funciones de relevancia pública

En el punto de mira de las compliance están, por supuesto, los funcionarios con competencias para la actuación pública deseada ${ }^{106}$. Así, en el ámbito de la contratación pública, desde el funcionario que decide acerca de las bases del concurso o contrato hasta el que emite el informe previo o el que resuelve definitivamente ${ }^{107}$. A pesar de que no todos tengan competencia directa para adoptar la resolución pueden incidir sobre ella y cobrar por hacerlo, supuesto en el que podría plantearse el delito de cohecho respecto de cada uno de ellos, además de la prevaricación de quien resuelve, con exclusión aquí de las personas jurídicas que no responden por este último delito.

Por supuesto, también entran en el ámbito de preocupaciones de las compliance quienes sin tener condición administrativa de funcionario ejercen funciones de relevancia pública ${ }^{108}$. El problema está en la concreta delimitación de este segundo círculo de sujetos que por la vía del art. $423 \mathrm{CP}^{109}$ puede alcanzar

105 Acerca de la posición de los particulares en los delitos de corrupción, por todos, DE LA MATA BARRANCO, N.: La respuesta a la corrupción pública. Tratamiento penal de la conducta de los particulares que contribuyen a ella, Comares, Granada, 2004.

106 Huelga abundar acerca del carácter material del concepto penal de funcionario recogido en el art. $24 \mathrm{CP}$ con carácter general, y el art. 423 para el delito de cohecho. Al respecto, véase el art. 1, pár. 28 del Rapport explicatif de la Convention pénale sur la corruption del Consejo de Europa, Strasbourg, 27.I.1999: "La priorité est donc donnée à la définition pénale".

107 Respecto de las distintas fases del procedimiento administrativo y los funcionarios en riesgo de corrupción en cada una de ellas, véase la Guía sobre medidas contra la corrupción en la contratación pública y en la gestión de la Hacienda pública. Buenas prácticas para lograr el cumplimiento del artículo 9 de la Convención de las Naciones Unidas contra la Corrupción, 2014, pág. 5.

108 Informe de evaluación relativo a España del Tercer ciclo de evaluación del GRECO Incriminación (ETS 173 y 191, GPC 2) (Tema 1), 15-5-2009, pár. 14.

109 art. 423: "Lo dispuesto en los artículos precedentes será igualmente aplicable a los jurados, árbitros, mediadores, peritos, administradores o 
a los concesionarios o responsables de empresas públicas o mix$\operatorname{tas}^{110}$. El resto, podrían remitirse, en su caso, al tipo de corrupción privada del art. 286 bis CP que podría actuar de cláusula de cierre del sistema ${ }^{111}$.

En estos supuestos, la persona jurídica donante podría responder por los pagos a cualquiera de ellos por la vía de las distintas modalidades de corrupción activa en la esfera pública o privada. No así la organización jurídico pública al servicio de la que actuara el receptor del pago por la exclusión de las mismas del ámbito de la RPPJ ex art. 31 quinquies.

b) El funcionario extranjero o internacional

En la actualidad, es comúnmente aceptada la necesidad de incluir a los funcionarios extranjeros e internacionales entre los posibles targets de la corrupción. Así se recoge en nuestro

interventores designados judicialmente, administradores concursales o a cualesquiera personas que participen en el ejercicio de la función pública." La especial relevancia de árbitros y jurados como posibles agentes u objeto de corrupción es puesta de manifiesto en el Protocolo adicional al Convenio penal contra la corrupción del Consejo de Europa, de 15 de mayo de 2003. Al respecto, por todos, VALEIJE ÁLVAREZ, I.: "Reflexiones sobre los conceptos penales de funcionario público, función pública y "personas que desempeñan una función pública", CPC, 62, 1997.

110 En este sentido, la Recomendación No. $R$ (2000) 10 insta a extender el concepto de funcionario a los empleados por entidades privadas que desarrollen funciones públicas (art. 1); asimismo, el art. 2, a) ii) de la Convención de las Naciones Unidas contra la corrupción, de 2004, incluye en el concepto de "funcionario público" a "toda otra persona que desempeñe una función pública, incluso para un organismo público o una empresa pública, o que preste un servicio público, según se defina en el derecho interno del Estado Parte y se aplique en la esfera pertinente del ordenamiento jurídico de ese Estado Parte.

Sobre la incidencia de la naturaleza de la empresa en la apreciación del delito de malversación, ATS (Sala 2a) 25-5-2017.

111 En este sentido, con especial mención a la resbaladiza frontera entre la esfera pública y la privada y sus repercusiones sobre la delimitación típica de las figuras de corrupción, véase el Informe de evaluación relativo a España Incriminación (ETS 173 y 191, GPC 2) (Tema 1) Adoptado por el GRECO En su 42 Reunión Plenaria (Estrasburgo, 11-15 Mayo 2009), Tercera Ronda de evaluación, pár. 95. 


\section{Código penal que, tras algunas reformas y vacilaciones por parte de nuestro legislador, ha abordado esta compleja cuestión tanto desde la perspectiva sustantiva ${ }^{112}$ como procesal $^{113}$.}

112 Como es sabido, desde la aprobación del vigente Código penal, en 1995, el concepto de funcionario que se recoge en el art. $24 \mathrm{CP}$, entre las Disposiciones comunes, ya incluía algunos al servicio de organismos internacionales, como los miembros del Parlamento Europeo. Con todo, esta tímida incursión en el concepto internacional de funcionario público era relativizada por quienes consideraban que el funcionario europeo era en el fondo un funcionario nacional. Si a ello se añade que el art. 24 no hacía referencia a otros funcionarios al servicio de las instituciones europeas, el avance sólo podía calificarse de tímido.

El primer cambio importante en la materia llega con la LO 3/2000, por la que se introdujo el art. 445 bis CP que tipificó por primera vez el delito de corrupción en las transacciones comerciales internacionales, hoy en el art. 286 ter, después de haber pasado, entre 2003 y 2015, por el art. 445 . Sin embargo, los funcionarios extranjeros o al servicio de organismos internacionales continuaban quedando al margen de las posibilidades aplicativas del resto de delitos de corrupción pública, entendida en sentido amplio, tradicionalmente restringida a la protección de la Administración pública española.

No es sino hasta la reforma de 2010 cuando se ampliaría el ámbito aplicativo típico del delito de cohecho mediante la definición del concepto penal de funcionario válido para este delito en el art. $427 \mathrm{CP}$, que debía complementar las previsiones del más genérico art. $24 \mathrm{CP}$. A partir de ese momento, el ámbito subjetivo del delito de cohecho se extendería también a los funcionarios de la Unión europea o de otros Estados miembros.

Ampliación que continuaría con la reforma de 2015, en virtud de ulterior extensión del ámbito subjetivo del art. 427 a los funcionarios de ya cualquier Estado extranjero u organismo internacional, con directa repercusión sobre el ámbito subjetivo del delito de cohecho, a la vez que el delito de corrupción en las transacciones comerciales internacionales del art. 286 ter se ampliaba en sentido inverso a los funcionarios nacionales, en virtud de la remisión de su primer apartado, párrafo tercero a los arts. 24 y 427. Situación que como es obvio provocará previsibles problemas concursales, sobre los que no es posible entrar aquí, pero que a medida que se vaya aplicando el precepto, prácticamente inédito (con la práctica única excepción de la SAN 3/2017, 23-2), se comprobará.

113 En este sentido, por Ley Orgánica 1/2014, 13-3 se reformó el art. 23.4 LOPJ para extender el principio de jurisdicción internacional a los siguientes supuestos, entre otros:

“n) Delitos de corrupción entre particulares o en las transacciones económicas internacionales, siempre que: 
Si la Convención OCDE sobre corrupción en las transacciones comerciales internacionales de 1997 determinó la tipificación de la corrupción (activa) del funcionario público extranjero o al servicio de organizaciones internacionales (con la LO 3/2000), la Convención penal sobre la corrupción del Consejo de Europa de 1999 está tras la ampliación del delito de cohecho (activo y pasivo) a los funcionarios de la UE y sus Estados miembros (desde la LO 5/2010) y el resto de funcionarios extranjeros e internacionales ${ }^{114}$ (desde la LO 1/2015).

Por lo tanto, también las prebendas ofrecidas a funcionarios extranjeros o al servicio de organizaciones internacionales deberán estar en el punto de mira de las pautas anticorrupción, con independencia de si tienen lugar en España o en el extranjero, si bien, en este último caso, la perseguibilidad queda restringida a los supuestos recogidos en el art. 23.4 LOPJ, que esencialmente son aquellos en los que el autor sea español o residente o al servicio de una empresa vinculada con España.

$1 .^{\circ}$ el procedimiento se dirija contra un español;

$2{ }^{\circ}$ el procedimiento se dirija contra un ciudadano extranjero que resida habitualmente en España;

3. ${ }^{\circ}$ el delito hubiera sido cometido por el directivo, administrador, empleado o colaborador de una empresa mercantil, o de una sociedad, asociación, fundación u organización que tenga su sede o domicilio social en España; o,

4. ${ }^{\circ}$ el delito hubiera sido cometido por una persona jurídica, empresa, organización, grupos o cualquier otra clase de entidades o agrupaciones de personas que tengan su sede o domicilio social en España."

114 Sobre el compromiso con la lucha contra la corrupción en cualquier Estado, véase el Rapport explicatif de la Convention pénale sur la corruption del Consejo de Europa, Strasbourg, 27.I.1999, art. 50, pár. 49: "En prévoyant une incrimination de corruption pour les agents publics étrangers de n'importe quel pays, cet article va au delà des dispositions de la Convention de L'Union Européenne. Il va également au delà de la disposition contenue dans l'accord de l'OCDE, et ce à un double titre. Tout d'abord, elle concerne à la fois le volet actif et le volet passif."(...) l'inclusion de la corruption passive d'agents publics étrangers dans l'article 5 procède du souci de montrer la solidarité de la communauté des Etats face à la corruption, partout oùcelle-ci se produit." 
A estos efectos, será importante destacar la necesidad de conocer la legislación de los países en los que operen las empresas $^{115}$, por cuanto podrían declarar atípicos determinados pagos de favor. Ahora bien, que deban tenerse en cuenta los supuestos de expresa declaración de atipicidad contemplados en otros ordenamientos no significa que pueda invocarse la mayor laxitud en la efectiva persecución de la corrupción en el país extranjero cuando precisamente la función de la norma reside en perseguir aquí lo que no se persigue en el extranjero, garantizando unos estándares mínimos en el mercado internacional ${ }^{116}$.

c) Los intermediarios o beneficiarios

Tanto el cohecho como el tráfico de influencias o el propio delito de financiación ilícita de partidos contemplan la intervención de terceros ajenos al funcionario competente sea como intermediarios o beneficiarios. Es más, en el tráfico de influencias es el tercero el que concentra el protagonismo y responsabilidades penales. Lo mismo sucede con el delito de financiación ilícita que se extiende a las donaciones directas o por persona interpuesta, y castiga en especial a quienes participen en estructuras u organizaciones destinadas a financiar a los partidos (art. 304 ter $\mathrm{CP}$ ). Todo ello nos sitúa ante un fenómeno en el que es habitual la actuación en red o de forma organizada ${ }^{117}$, que necesariamente deberá reflejarse en la extensión del espectro de sujetos en el punto de mira de las compliance.

115 Así se subraya en la Programa anticorrupción de ética y cumplimiento para las empresas. Guía práctica, UNODC, 2013, pág. 13.

$116 \mathrm{Al}$ respecto, es de especial interés la afirmación contenida en el pár. 210 de la Guía legislativa para la aplicación de la Convención de las Naciones Unidas contra la Corrupción, 2a. ed. revisada, 2012, según el que: "cada funcionario público tiene el deber de ejercer su criterio o arbitrio imparcialmente y que se trata de una definición "autónoma" que no requiere prueba de la ley o de los reglamentos del país del funcionario de la organización internacional pertinente (A/58/422/ Add.1, párrafo 24)."”

117 No en balde la Convención de las Naciones Unidas Contra la delincuencia organizada Transnacional de 2004, sitúa en el foco de especial atención al fenómeno de la corrupción (art. 8). 
Empezando por las tipicidades de cohecho nacional e internacional ${ }^{118}$, en ambas se recoge tanto la actuación "por si o persona interpuesta" 119 como "en beneficio/provecho propio $o$ de un tercero" ${ }^{120}$. Supuestos que encajan en el concepto de "corrupción trilateral o triangular", en el que junto al funcionario competente y quien paga por sus servicios aparece un "ex-

118 Sobre el fenómeno de los intermediarios llama la atención la Guía de buenas prácticas sobre la aplicación de determinados artículos del Convenio sobre lucha contra la corrupción de funcionarios públicos extranjeros en las transacciones comerciales Internacionales, en el Anexo 1 al Documento sobre el Convenio OCDE, del Ministerio de economía y competitividad, Ministerio de justicia Madrid, 2015, letra C).

Al respecto también, FABIÁN CAPARRÓS, E.: La corrupción de agente público, cit., págs. $92 \mathrm{ss}, 98$, quien observa que la intermediación ha estado tradicionalmente ligada al cohecho pasivo y no así al activo, aunque en la actualidad, siguiendo las pautas convencionales, también se encuentre en el tipo de corrupción en las actividades económicas internacionales que sólo recoge la forma activa.

119 Como señala VÁZQUEZ-PORTOMEÑE SEIJAS, F.: Los delitos contra la Administración Pública, cit., págs. 412 ss., si bien es cierto que la posibilidad de actuación a través de persona interpuesta no se recoge explícitamente en todas las modalidades típicas (como por ejemplo, el supuesto de aceptación de ofrecimiento o promesa del art. 419 y, en la regulación originaria del actual Código, en el cohecho impropio), ello no tiene por qué conducir a su automática exclusión, pág. 418.

120 Así se recoge explícitamente en la Guía legislativa para la aplicación de la Convención de las Naciones Unidas contra la Corrupción $2^{\mathrm{a}}$ ed. revisada, 2012, pár. 197 para el cohecho activo: "El beneficio indebido no tiene que concederse inmediata ni directamente a un funcionario público del Estado. Podrá prometerse, ofrecerse o concederse directa o indirectamente. El regalo, la concesión u otro beneficio podrá otorgarse a otra persona, como un familiar, o a una organización política"; lo mismo para el cohecho pasivo, en el pár. 201. Del mismo modo, en la Guía sobre medidas contra la corrupción en la contratación pública y en la gestión de la Hacienda pública. Buenas prácticas para lograr el cumplimiento del artículo 9 de la Convención de las Naciones Unidas contra la Corrupción, 2014, pág. 7: "El receptor del soborno es por lo general un funcionario de contratación de la entidad contratante encargado de adjudicar y/o gestionar el contrato público. Con frecuencia, el pago por concepto de soborno no es efectuado directamente por el licitante al personal de contratación, sino que pasa por un agente, consultor u otro intermediario. 'En el mismo sentido, el Convenio Penal sobre la Corrupción del Consejo de Europa, de 27-1-1999, sobre el 
traneus" u "outsider" 121 que tanto puede ser el correo como el beneficiario o ambas cosas a la vez ${ }^{122}$. Otra cosa es que, como advierte VÁZQUEZ-PORTOMEÑE ${ }^{123}$, la inclusión de una explícita mención al intermediario no sea requisito absoluto de la posibilidad de persecución penal de quien actúa a través de éste.

El papel del intermediario es todavía más visible o central en el tráfico de influencias en el que por definición quien negocia es el tercero ajeno a las competencias públicas sobre las que se mercadea ${ }^{124}$, pero del que cabe advertir que -a diferencia de lo que prevén los textos internacionales ${ }^{125}$-, el tipo español

que el Rapport explicatif de la Convention pénale sur la corruption del Consejo de Europa, Strasbourg, 27.I.1999 aclara que en la corrupción activa la ventaja: "il peut être aussi donné à un tiers tel qu'un membre de sa famille, une organisation à laquelle l'agent public appartient, le parti politique auquel il adhère", y que puede concederse directamente o a través de un intermediario, sea consciente o no del significado penal de su intervención, pár. 42: "Là encore, il peut y avoir intervention d'un intermédiaire; si tel est le cas, le champ de la corruption passive se trouve élargi, puisqu'il faut y inclure une action indirecte de la part de l'agent; en même temps, il s'ensuit nécessairement qu'on doit mettre en évidence le caractère délictueux du comportement de l'agent, indépendamment de la bonne foi ou de la mauvaise foi de l'intermédiaire." Todo ello sin perjuicio de las consecuencias que se deriven de la concurrencia o no del dolo típico, a los efectos de considerar al intermediario como instrumento que actúa bajo error o partícipe.

También, FABIÁN CAPARRÓS, E.: La corrupción de agente público, cit., págs. 92 y ss. y 98.

121 Según terminología del Rapport explicatif de la Convention pénale sur la corruption del Consejo de Europa, Strasbourg, 27.I.1999, art. 12, pár. 66.

122 FABIÁN CAPARRÓS, E.: La corrupción de agente público, cit., pág. 98.

123 VÁZQUEZ-PORTOMEÑE SEIJAS, F.: Los delitos contra la Administración Pública, cit., pág. 418.

124 En este sentido, como declara el Rapport explicatif de la Convention pénale sur la corruption del Consejo de Europa, Strasbourg, 27.I.1999, art. 12, pár. 64: "L'incrimination du trafic d'influence cherche à atteindre l'entourage de l'agent ou le parti politique auquel il adhère et à sanctionner le comportement des personnes qui, proches du pouvoir, tentent d'obtenir des avantages en raison de leur situation, contribuant ainsi à l'instauration d'un climat de corruption. Cela permet aux Parties Contractantes de s'attaquer à ce que l'on appelle la "corruption ambiante»

125 Así art. 12 del Convenio del Consejo de Europa contra la corrupción. 
contenido en el art. $430 \mathrm{CP}$ sólo castiga la forma pasiva protagonizada por quien vende la influencia y no así la activa a cargo de quien la compra. De modo que, en principio, quedarían fuera las empresas que compran la influencias.

Otra cosa es que la empresa donante pueda ser castigada como inductora del ejercicio de influencias tipificado en los arts. 428 o 429 CP. Aunque no deja de ser paradójico que lo expresamente excluido del tipo de tráfico de influencias (art. $430 \mathrm{CP}$ ) se incluya por la vía de la participación en otro delito, así se admite en Doctrina y jurisprudencia. En todo caso, en virtud del principio de accesoriedad de la participación, no puede olvidarse que para proceder por esta vía es preciso que se haya dado inicio a la ejecución del delito principal y por lo tanto al ejercicio de la influencia. Así, no obstante para el castigo del receptor basta con la solicitud o aceptación de la dádiva o promesa, para el castigo del donante será preciso el posterior inicio del ejercicio de influencia.

Por fin, en cuanto al delito de financiación ilícita de partidos, el funcionario competente no es ni tan sólo mencionado, pues el ámbito típico queda acotado a la relación directa del donante con el partido. Con todo, ello no empece que si la donación se condiciona a que el partido ejerza su influencia sobre el funcionario competente pueda apreciarse además, el delito de tráfico de influencias.

En suma, los códigos de conducta empresarial no pueden ceñir su foco de atención al estricto círculo de funcionarios competentes cuando es evidente que el ámbito aplicativo de las distintas tipicidades podría abarcar desde la entrega del soborno al bedel para su traslado al funcionario (con independencia de si el primero actúa dolosamente o bajo error ${ }^{126}$ ), hasta la contratación de familiares o amigos a instancias del primero o donaciones a partidos o sus fundaciones para que influyan en aquél.

126 Sobre la willful blindness del intermediario, FABIÁN CAPARRÓS, E.: La corrupción de agente público, cit., pág. 114, nota 123. 
En la lista de posibles beneficiarios, los instrumentos internacionales llaman especial atención sobre las entidades sin ánimo de lucro ${ }^{127}$, que podrían ser receptoras de los pagos típicos del cohecho o tráfico de influencias, según el caso ${ }^{128}$.

Más difícil es elaborar una lista completa de sujetos que puedan identificarse ex ante como focos de riesgo penal, pues las posibilidades de pactos corruptos no quedan cerradas a ámbitos perfectamente delimitados como los que caracterizan las incompatibilidades ${ }^{129}$. En todo caso, como ya se ha advertido, cuanto más se amplíe el radio de acción de las normas de conducta más atención deberá prestarse al posible conflicto entre las necesidades de prevención de la corrupción y el libre ejercicio de otros derechos o libertades como el derecho a aspirar a determinados puestos o cargos por parte del círculo de personas próximas al funcionario competente o el ejercicio de la libertad de empresa.

127 Así, respecto del delito de corrupción en las transacciones comerciales internacionales, GALÁN MUÑOZ, A.: "Globalización, Corrupción internacional y Derecho penal. Una primera aproximación a la regulación penal de dicho fenómeno criminal tras la LO 1/2015", Estudios penales y criminológicos, núm. 36, 2016, pág. 627.

128 Posibilidad expresamente recogida en la Guía legislativa para la aplicación de la Convención de las Naciones Unidas contra la Corrupción Segunda edición revisada, 2012, pár. 315, que reconoce que, en muchos casos "En muchos casos los delitos graves y complejos son cometidos por entidades jurídicas como empresas, sociedades u organizaciones de beneficencia, o por conducto de ellas o a su amparo."

Al respecto, véase el "Caso Palau" (SAP Barcelona 29-12-2017), y comentario a la fase de instrucción en CUGAT MAURI, M.: "La responsabilidad penal de los cargos de los partidos”, cit., págs. 251 ss.

129 Así, arts. 11 ss de la Ley 3/2015, 30-3; art. 71 de la Ley 9/2017, de 8 de noviembre, de Contratos del Sector Público, por la que se transponen al ordenamiento jurídico español las Directivas del Parlamento Europeo y del Consejo 2014/23/UE y 2014/24/UE, de 26 de febrero de 2014. 


\section{Bibliografía}

CUGAT MAURI, M., "El tráfico de influencias en cuatro sentencias", Jueces para la democracia, núm. 28, 1997. "El tráfico de influencias: un tipo prescindible", Revista Electrónica de Ciencia Penal y Criminología, 2014.

"La responsabilidad penal de los cargos de los partidos políticos: alternativas típicas y zonas oscuras", en GARCÍA ARÁN y BOTELLA (Dirs.), Responsabilidad jurídica y política de los partidos en España, Tirant lo Blanch, Valencia, 2018.

DE LA MATA BARRANCO, N., La respuesta a la corrupción pública. Tratamiento penal de la conducta de los particulares que contribuyen a ella, Comares, Granada, 2004.

DE LA NUEZ, E., "Partidos políticos y transparencia", en NIETO MARTÍN, A./MAROTO CALATAYUD, M. (Dirs.), Public compliance. Prevención de la corrupción en administraciones públicas y partidos políticos, Ediciones de la Universidad de Castilla-la Mancha, Cuenca, 2014.

DÍAZ MAROTO Y VILLAREJO, J., "Sobre la práctica del lobby y los delitos de tráfico de influencias", Diario La Ley, núm. 7286, 18-11-2009, D-356.

FABIÁN CAPARRÓS, E., La corrupción de agente público extranjero e internacional, Tirant lo Blanch, Valencia, 2003.

FERNÁNDEZ GARCÍA, J., "Algunas reflexiones sobre la corrupción política”, en FABIÁN CAPARRÓS y PÉREZ CEPEDA, Estudios sobre corrupción, Ratio legis, Salamanca, 2010.

FOFFANI, L. en FOFFANI y NIETO MARTÍN, A., "Corporate Governance y administración desleal. Casos y problemas de derecho comparado europeo", Revista penal, núm. 17, 2006.

FORTI, G.: "L'insostenibile pesantezza della "tangente ambientale": Inattualità di disciplina e disagi applicativi nel 
rapporto Corruzione-concussione", en Riv. it. dir. e proc. pen., fasc.2, 1996.

GALÁN MUÑOZ, A., "Globalización, Corrupción internacional y Derecho penal. Una primera aproximación a la regulación penal de dicho fenómeno criminal tras la LO 1/2015", Estudios penales y criminológicos, núm. 36, 2016.

GÓMEZ BENÍTEZ, JM., "Financiación ilegal de partidos políticos y corrupción", en CASTRO MORENO/OTERO GONZÁLEZ, Prevención y tratamiento punitivo de la corrupción en la contratación pública y privada, Dykinson, 2016.

GÓMEZ RIVERO, M.C., "El castigo penal de la corrupción en el ámbito del llamado sector público instrumental", en Revista Electrónica de Ciencia Penal y Criminología, núm.18-06, mayo de 2016

"Derecho penal y corrupción: acerca de los límites de lo injusto y lo permitido", en Estudios Penales y Criminológicos, Vol. XXXVII, 2017.

GÓRRIZ ROYO, E., "Corrupción urbanística: análisis criminológico y respuestas jurídico-penales", en JAREÑO LEAL, a (DIR.), Corrupción pública: cuestiones de politica criminal”, iustel, Madrid, 2014.

GUICHOT, E., "La nueva regulación legal de la transparencia, el acceso a la información pública y el buen gobierno como mecanismo de lucha contra la corrupción y regeneración democrática", en JAREÑO LEAL, a (DIR.), Corrupción pública: cuestiones de política criminal", iustel, Madrid, 2014.

JAREÑO LEAL, A., "La corrupción en la contratación pública", en JAREÑO LEAL, a (DIR.), Corrupción pública: cuestiones de politica criminal”, iustel, Madrid, 2014.

MAROTO CALATAYUD, M., La financiación ilegal de partidos políticos. Un análisis político criminal, Marcial Pons, Madrid, 2015. 
MORALES PRATS, F Y RODRÍGUEZ PUERTA, MJ., "Comentario al art. 419”, en QUINTERO OLIVARES (dir.), Comentarios al Código penal español, Aranzadi, $7^{\mathrm{a}}$. Ed., 2016.

MUÑOZ CUESTA, J., "La financiación ilegal de partidos políticos. Estado actual de la cuestión. Examen delo nuevo delito de financiación ilegal de partidos políticos", www. fiscal.es.

NAVARRO CARDOSO, F., "Cohecho pasivo subsiguiente o por recompensa", Revista electrónica de ciencia penal y criminología, 18-25, 2016.

NIETO MARTIIN, A., en GOMEZ RIVERO/MARTINEZ GONZALEZ/NUÑEZ CASTAÑO, Nociones fundamentales del derecho penal, 3a ed., Madrid, 2015

NUÑEZ CASTAÑO, E., "La cuestionable regulación penal de los delitos de financiación ilegal de partidos políticos", Revista penal, 39/2017.

OFICINA ANTIFRAU DE CATALUNYA, La gestió dels conflictes d'interès en el sector públic de Catalunya, Barcelona, 2016.

OLAIZOLA NOGALES, I, “«Medidas de regeneración democrática». La nueva regulación de la financiación de los partidos políticos en España", http://revista-estudios.revistas.deusto.es/article/view/186/306

"El delito de financiación ilegal de partidos políticos en la reforma del CP”, Diario La Ley, 8516, 10-4-2015.

PADOVANI, T., "Il problema «Tangentopoli» tra normalità dell'emergenza ed emergenza della normalità", Rivista italiana di diritto e procedura penale, núm. 2-3, 1996.

PUENTE ABA, LM. (dir.), "Financiación ilegal de partidos políticos (art 304 bis CP), en Comentarios a la reforma del Código penal de 2015, en GORRIZ ROYO/MATALLÍN EVANGELIO (coord.). GONZALEZ CUSSAC (dir.), $2^{\mathrm{a}}$ ed,Valencia, 2015.

QUINTERO OLIVARES. G., QUINTERO OLIVARES, G., Los delitos especiales: y la teoría de la participación en el derecho penal español, CYMIS, 1974. 
"Los programas de cumplimiento normativo y el Derecho penal", en DEMETRIO CRESPO (coord.) Derecho penal económico y derechos humanos, UCLM, Tirant lo Blanch, 2018.

RAMOS RUBIO, C., "Del delito de cohecho: mano «más» dura «todavía» contra la corrupción nacional e internacional, arts. 419, 420, 421, 422, 423, 424, 425, 426, 427, 430, 439 y 445 ", en QUINTERO OLIVARES (dir.), La Reforma Penal de 2010: análisis y comentarios, Aranzadi, Cizur Menor, 2010

SANTANA VEGA, D., "El delito corporativo de incumplimiento en la prevencion de sobornos (Bribery act 2010)", Revista Electrónica de Ciencia Penal y Criminología, 17-15, 2015.

SCHICKORA, T., "Bringing the Four-Eyes-Principle to the Lab", Munich Discussion Paper No. 2011-3, Department of Economics University of Munich Volkswirtschaftliche Fakultät, Ludwig-Maximilians-Universität München, http://epub.ub.uni-muenchen.de/12160/.

VALEIJE ÁLVAREZ, I., "Aspectos problemáticos del delito de concusión (diferencias con el cohecho)", Revista general de derecho, 597/1994.

El tratamiento penal de la corrupción del funcionario: el delito de cohecho, Edersa, Madrid, 1996.

"Reflexiones sobre los conceptos penales de funcionario público, función pública y "personas que desempeñan una función pública”, CPC, 62, 1997.

VÁZQUEZ-PORTOMEÑE SEIJAS, F., Los delitos contra la Administración Pública. Teoría general, INAP, Universidad de Santiago de Compostela, 2003.

"Sobre el cohecho por $<$ actos propios del cargo $>$ y sus relaciones con el delito de exacciones ilegales", Cuadernos de política criminal, 116/2015.

"El tráfico de influencias y su criminalización en el contexto internacional", Diritto penale contemporáneo, 2015 . 
"Política criminal del cohecho impropio: presupuestos para su reforma en el Código penal español", Diario La Ley, $\mathrm{n}^{\circ}$ 8526, 2015, 24-4 en http://diariolaley.laley.es/

VILLEGAS GARCÍA, MA., ENCINAR DEL POZO, MA., "La responsabilidad penal de las personas jurídicas. La Jurisprudencia de la Sala de lo Penal del Tribunal Supremo", Diario La Ley, 26-12-2017. 